\title{
ENSUCIAMIENTO DE FACHADAS PÉTREAS POR LA CONTAMINACIÓN ATMOSFÉRICA. EL CASO DE LA CIUDAD DE VALLADOLID, ESPAÑA
}

\author{
(CONTAMINATION OF STONE FAÇADES BY ATMOSPHERIC POLLUTION. \\ THE CASE OF VALLADOLID, SPAIN)
}

\author{
Francisco Javier León Vallejo, Dr. Arquitecto
}

\section{RESUMEN}

El ensuciamiento de fachadas de materiales pétreos, debido a los contaminantes de la atmósfera, es un fenómeno de transcendencia creciente, pues, además de ir asociado generalmente a otros procesos de deterioro de la piel de los revestimientos, incide directamente en la imagen y carácter del entorno urbano en que nos movemos.

El proceso de ensuciamiento es complejo puesto que implica unas variables muy diversas: Las particulas contaminantes que se depositan y adhieren sobre los paramentos. EI microclima con sus meteoros, viento, lluvia, temperatura y vapor de agua, principalmente. Los materiales con sus caracteristicas de porosidad, textura superficial, color, dureza, etcétera. La situación y composición de las fachadas, siendo determinantes factores como: proporciones; exposición al agua viento; abrigo por otros edificios; tamaño y disposición de sus planos macizos y vanos; inclinación y curvatura de los planos; elementos volados y retranqueados; componentes ornamentales y singulares, como relieves, impostas, cornisas, vierteaguas y gárgolas.

Para analizar el ensuciamiento de Valladolid se estudió una muestra de edificios, empleando una ficha que contempla datos de localización y aspecto de las fachadas; las variables antes citadas y las características de las lesiones, a través de la definición de sus sintomas y causas.

El procesado de las fichas y la evaluación de los datos mediante "índices de riesgo de las variables", permitio cuantificar los resultados y proponer unas conclusiones en cuanto a la incidencia de los factores implicados. Además se proponen unos criterios a tener en cuenta en el proyecto como medios preventivos para evitar las suciedades más perjudiciales.

\section{SUMMARY}

Soiling of stony material façades because of the atmospheric pollutants is a phenomenom more and more important affecting directly on image and character of our urban around, besides it be generally bound to another damage processes of material skin.

Solling development is a complex one since it involves a lot of different variables: the particulate matter settled and bounded to the faces. The microclimate with its different meteors like wind, rain out and rain off, temperature and humidity. The materials and its features: porosity, from the obstacles to wind; size and disposition of wall planes and windows; linking and curving of planes; projections and offsets; decorative and singular components as reliefs, facias, cornices, flashing and spouts.

Building and façades specimen has been analyzed in order to know soiling state in Valladolid, using a special worksheet containing the location and look of faces; the before parameters and the damage features throug the account of its syntoms and motives.

The study of analytic cards and data evaluation by means of variables "risk index" have allowed quantify outputs and propose some conclusions about the factor's influence. Moreover any suggestions for design in order to prevent most harmful soiling are proposed.

\section{PRÓLOGO}

El problema del ensuciamiento como proceso de alteración de las fachadas de edificios se plantea en un contexto ambiguo, si se tiene en cuenta que su manifestación es esencialmente visual y, por tanto, estéti- ca, aunque con frecuencia coexista con lesiones físicas y químicas de los materiales de revestimiento.

La consideración "aparente" de este tipo de lesión ha supuesto su infravaloración en la práctica, al incidir en menor medida sobre la funcionalidad y la economía de 
los edificios. Y su resolución, dentro del campo del mantenimiento a largo plazo, es fruto muchas veces de decisiones coyunturales a escala urbana, alejadas del interés real de los usuarios acostumbrados, por lo demás, al lento envejecer de la imagen de las edificaciones que habitan.

Así, la política de actuación sobre edificios afectados es muy limitada y se reduce, en la práctica, a recursos de limpieza en edificios monumentales y a la renovación de tratamientos decorativos poco duraderos, generalmente en áreas céntricas o cascos antiguos, donde los efectos del tráfico, la densidad de edificación y la mayor antigüedad de los edificios, tienen mayores consecuencias para el ensuciamiento. Si a ello se suma la escasa conciencia social generalizada acerca de lesiones con repercusión estética, tendremos el cuadro aproximado de la situación real en nuestras áreas urbanas.

El ensuciamiento, como lesión estética, es difícil de valorar y normalizar. Es cierto que un templo gótico o un palacio del Renacimiento situados en área contaminada, presentarán un alto grado de suciedad para todo el mundo. Pero estos edificios, realizados seguramente con piedra porosa, se hallarán afectados, además, por sulfatación o cualquier otro tipo de corrosión. Ese factor, junto al valor efectivo de los edificios como símbolos arquitectónicos vivos o recuperables, influye más que su objetivo ensuciamiento sobre cualquier idea de restauración.

Tal sucede, por ejemplo, con la evolución de las fachadas recientes de hormigón y cerámica, cuyo ensuciamiento no deseado afecta muy poco a la estabilidad de los materiales. La alteración visual recibe entonces escasa atención si los usuarios y la sociedad en general, a través de sus representantes ideólogos o administradores, no perciben en esos deterioros una disminución de la calidad de vida.

Seria importante, pues, convenir en una necesidad de actuación no solamente paliativa sino también preventiva; y ésta debe fundamentarse en el acuerdo general de lo que podria considerarse como ensuciamiento lesivo para las fachadas. Es decir, establecer con claridad la diferencia entre la pátina de envejecimiento natural $e$ inevitable, y aquellos procesos que suponen una notable alteración de la imagen externa, pretendida por sus artifices, cuando el edificio alcanzó su materialidad.

El reto actual consiste en conocer, siquiera elementalmente, los criterios necesarios para proyectar fachadas que tengan en cuenta el envejecimiento y posean recursos suficientes para impedir procesos patológicos de ensuciamiento, acaso aún por definir con suficiente objetividad por críticos y expertos de la imagen y su impacto social.
El paso previo será, pues, delimitar lo aceptable de lo patológico o indeseable y la dilucidación de cuál debe ser el camino lógico para enfrentar el problema con una perspectiva amplia y total. Éste constaría de una etapa inicial de suficiente conocimiento de los mecanismos y factores implicados en la formación de un tipo de lesión de tal complejidad.

Con una base teórica suficiente, podría abordarse un análisis empírico de los modelos de ensuciamiento originados sobre la población arquitectónica existente. Dicha labor podría enfocarse de manera global, abarcando en lo posible una gama amplia de tipos de fachadas en relación a materiales, composición y ornamentación, asi como las diferentes situaciones externas con influencia en el proceso. $O$ también, con carácter particular estudiando, como se ha hecho en Francia y Suecia, un determinado material y una tipología constructiva limitada.

La suma e integración de ambos enfoques deberá componer, en el futuro, el cuerpo completo de la doctrina que ha de permitir abordar los dos últimos tramos del camino: la fijación de los criterios preventivos de la patología, referidos fundamentalmente al proyecto, y los procedimientos terapéuticos que, paradójicamente, se encuentran ya bastante estudiados y experimentados. Y, de este modo, obtener unas reglas básicas de diseño que deben posibilitar un control preventivo de la formación de las suciedades sobre las fachadas de nuevos edificios e, incluso, de los que sean objeto de rehabilitación o restauración.

La investigación que aquí se expone incide en las tres etapas primeras, antes citadas, del conocimiento general de la patología de ensuciamiento, con exclusión de análisis particularizados y de todo lo referente a tratamientos de mantenimiento y limpieza:

- Explicación y principios teóricos del fenómeno.

- Análisis experimental en un área edificada concreta.

- Conclusiones surgidas de las dos anteriores, conteniendo una síntesis de sugerencias para el proyecto.

\section{PARTE: FUNDAMENTOS TEÓRICOS}

\section{PARTICULAS CONTAMINANTES}

Las partículas que afectan al proceso de ensuciamiento son aquellas que, cualquiera que haya sido su formación, poseen radios superiores a una micra; y cuanto mayores sean, mayor será la influencia de las fuerzas gravitatorias y menor su sensibilidad a los fenómenos de difusión ligados a las turbulencias atmosféricas. 


\section{DEPOSICIÓN DE LAS PARTÍCULAS CONTAMINANTES}

Las partículas con diámetro superior a una micra constituyen el 97 por 100 del contenido de la contaminación atmosférica, que se eliminará principalmente por los mecanismos de la deposición seca. De esta fracción el 70 por 100 - con tamaños comprendidos entre 1 y $15 \mu \mathrm{m}-$, más de las dos terceras partes del total, se depositará sobre todo mediante la difusión turbulenta, y el 27 por 100 restante - los tamaños superioreslo hará por mecanismos gravitatorios (con aire en calma) o de impacto inercial (con aire en movimiento). Casi la totalidad de dichas partículas se depositará por vía seca en dos o tres días.

Con aire en calma, las particulas superiores a la micra estarán afectadas exclusivamente por la acción de la gravedad, lo que impediria su depósito sobre paramentos verticales o superficies inclinadas hacia abajo o invertidas, de no ser por las siguientes circunstancias: a) Elevada rugosidad del soporte. b) Existencia de cargas electrostáticas en las particulas, en el paramento o en ambos (electroforesis), de poca importancia en los casos de revestimientos pétreos. c) Existencia de movimientos convectivos por gradiente térmico (termoforesis), d) Aparición de otros movimientos foréticos, principalmente de condensación de vapor (efecto Stefan).

Con viento, la difusión turbulenta afecta fundamentalmente a las particulas de rango intermedio pero que, al engrosar el mayor porcentaje de las existentes, influirá decisivamente en el ensuciamiento de las superficies verticales y de las protegidas. Las partículas gruesas estarán afectadas por choque inercial, produciéndose la deposición siempre que la energia del rebote no supere a la fuerza de adhesión. Por las condiciones en que se verifica, las posibilidades de que esto suceda son inversamente proporcionales al tamaño de la partícula y a la perpendicularidad de la dirección del choque.

\section{ADHESIÓN DE LAS PARTÍCULAS CONTAMINANTES}

Los mecanismos fundamentales de adhesión para el tipo de contaminación, que genera el ensuciamiento a estudiar, son el gravitatorio y el de tensión superficial ligado al fenómeno de la adsorción, en presencia de alto contenido de humedad en el aire y en el paramento.

Cualquiera que sea el mecanismo de deposición, las particulas de suciedad que han tomado contacto con la superficie de la fachada y no han rebotado tras el choque, tienden a permanecer establemente adheridas, por los diversos medios de adhesión mecánica y específica.
El medio ligante utilizado por una particula no suele ser único y, por lo general, pueden llegar a utilizar dos o tres de ellos, según la naturaleza de los materiales y las condiciones ambientales. Como resultado se originan, desde un mero apoyo sobre una microplataforma (en cuyo caso la partícula es fácilmente barrida por un simple viento), hasta una verdadera aglutinación (encapsulación por yeso) que puede hacer imposible su eliminación si no es por medios de limpieza mecánicos.

\section{FACTORES QUE INFLUYEN EN EL ENSUCIAMIENTO}

\subsection{Agentes climáticos}

\subsubsection{El viento}

El viento ejerce una influencia clara en la dispersión y transporte de las emisiones de productos contaminantes, siendo su carácter beneficioso en relación a las áreas cercanas a las fuentes de emisión. Puede ser negativo al actuar como vehículo capaz de exponer a los efectos de la contaminación otras áreas incluso muy alejadas y no responsables de dichos vertidos.

Alli donde el viento no actúa directamente, puede acceder a través de turbulencias o masas desviadas y rasantes, con una fuerza que dependerá de la velocidad del viento y de la altura sobre el nivel del suelo. Esta acción indirecta puede arrastrar parte de las particulas más gruesas, solamente sedimentadas, o de las más pequeñas, por transferencia en régimen turbulento (Fig. 1).

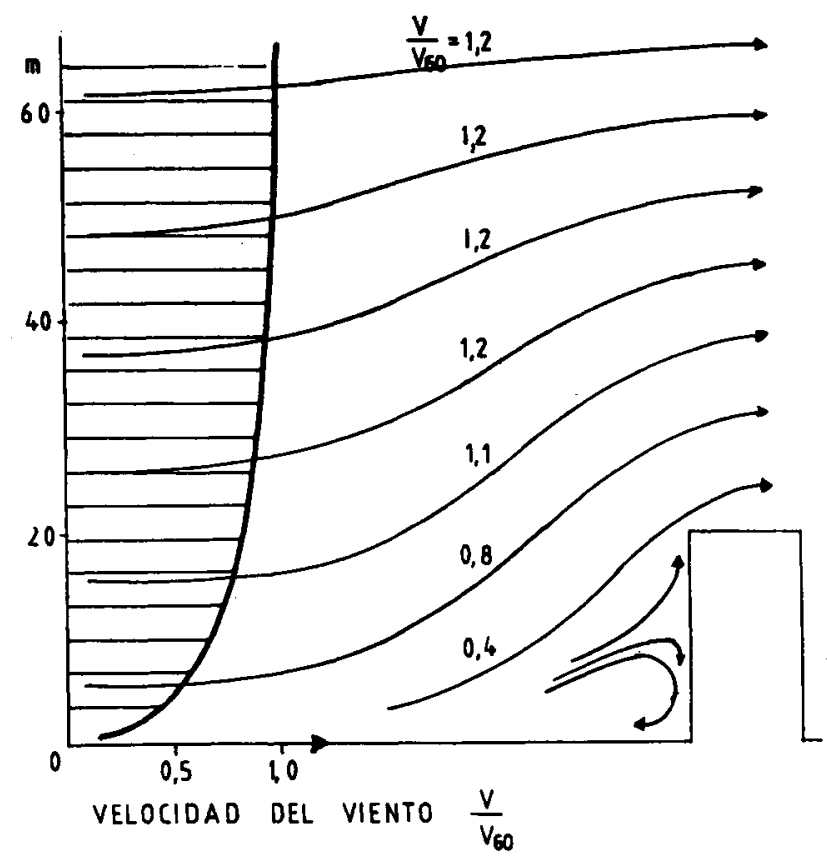

Fig. 1.-Modelo de flujo de viento dirigido contra un obstáculo longitudinal de ángulos rectos. Distribución de la velocidad para un terreno edificado (3). 
El efecto abrasivo o de limpieza en seco por el viento tiene una importancia relativa. Suele ser mayor en las partes más expuestas de la fachada, como esquinas laterales o en la parte superior próxima a la cornisa; también cuando la capa exterior de revestimiento se halla suficientemente alterada, como en la caolinización de feldespatos, para permitir el arrastre apreciable de material.

Sin embargo, en las partes bajas de fachada, con viento incidente de menor intensidad y desviado en torbellinos rasantes, así como en las partes abrigadas por salientes u obstáculos, junto a las que aparecen zonas de remanso, la fuerza de abrasión disminuye considerablemente, pasando a ser superior la tasa de deposición. La pátina, en estas partes, irá aumentando lentamente si la acción del viento no es reforzada por el lavado ocasionado por la lluvia.

\subsubsection{La lluvia batiente}

La cantidad de agua de lluvia que logra alcanzar la superficie de una fachada es menos de la mitad de la teórica que atraviesa una sección de aire de similar tamaño y posición. Ello indica que más de la mitad de ese total se pierde fuera de su alcance, debido a las desviaciones de las trayectorias de las gotas provocadas por el flujo de viento en su intento de rebasar el obstáculo.

Lo anterior ocurre, además, en los casos de fachadas exentas y viento ortogonal; las situaciones de hecho deben ser, por fuerza, menos favorables, en el sentido de que será aún menor la lluvia que bate la fachada.

La lluvia golpea principalmente la parte superior de la fachada, asi como los bordes laterales, si es exenta. Esto sucede con bastante independencia de la intensidad del fenómeno lluvioso, tal como se aprecia en la figura 2.

La lluvia, impulsada por el viento, es afectada cuando encuentra zonas de viento de diferente velocidad o dirección; su acomodación a la nueva situación es casi imposible al tropezar con pequeños obstáculos, como elementos saledizos de la fachada, viéndose abocada a chocar contra ellos y realizar asi un buen lavado. Si encuentra un obstáculo del rango de un edificio, y en situación favorable, tendrá más tiempo de desviarse acompañando las trayectorias del viento, si bien dificilmente alcanza desviaciones superiores a 2 metros en vertical (contra la gravedad) y 4 en horizontal, pudiendo pues rebasar mejor dichas fachadas.

En las partes inferiores de las fachadas las trayectorias de la lluvia son casi paralelas, es decir, verticales, por lo cual resulta muy difícil el lavado de los paños verticales por el agua de lluvia batiente.
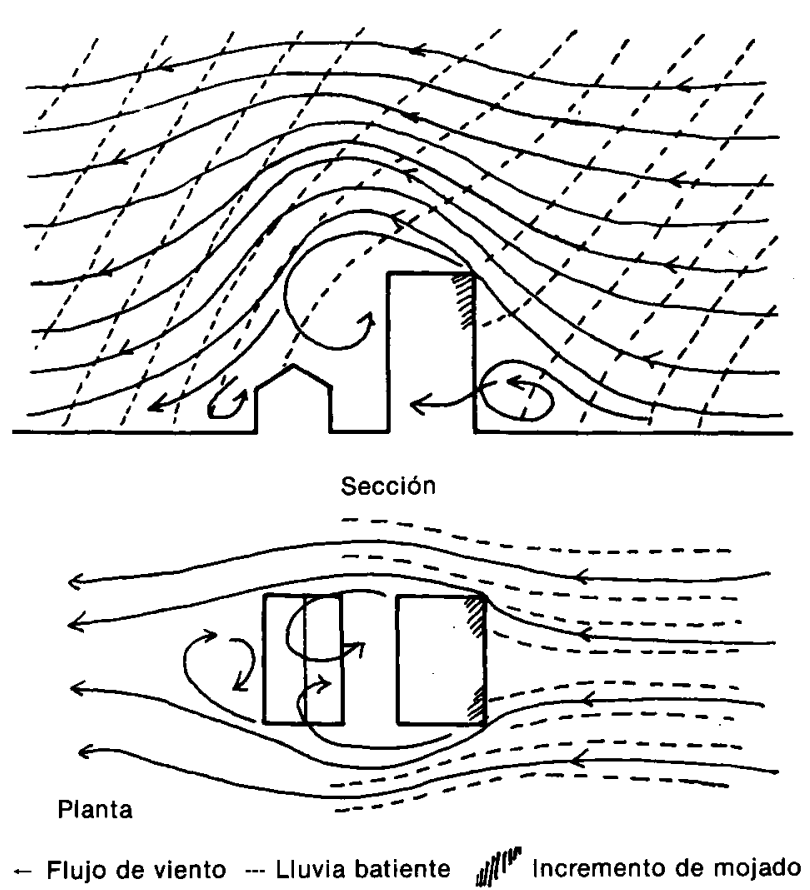

Fig. 2.-Actuación del par vientollluvia sobre edificios con diferente grado de protección.

\subsubsection{La lluvia escurrida}

El agua batiente que accede a las fachadas durante la Iluvia rebota hacia el exterior 0 , lo que es normal, queda atrapada por la superficie, siendo parcialmente succionada por capilaridad y adsorbida por tensión en la superficie. Al saturarse el material, o en ciertas circunstancias, el agua restante comienza a deslizarse.

La lluvia capaz de escurrir por la fachada lo hace en forma de fina lámina o película, muy sensible a las irregularidades del paramento, y con baja velocidad, siendo durante su trayectoria descendente absorbida continuamente por el material de revestimiento y su capa de suciedad.

Las condiciones para la absorción y la formación de escorrentía, así como los lapsos en que se producen esos fenómenos, pueden averiguarse a través del factor de absorción y experimentalmente, según la figura 3.

Una porción de las partículas de suciedad existentes sobre la fachada o aportadas por la lluvia penetran en la porosidad abierta con el agua absorbida o succionada, se haya o no formado ya la lámina discurrente, permaneciendo el resto adheridas, o siendo arrastradas por la escorrentía.

El agua deslizante produce una ligera erosión físicoquímica sobre el material, lo que va a favorecer el es. tablecimiento de caminos preferentes. Pero el efecto fundamental, en relación con el ensuciamento, es el de lavado $o$ arrastre parcial o total de las partículas de 


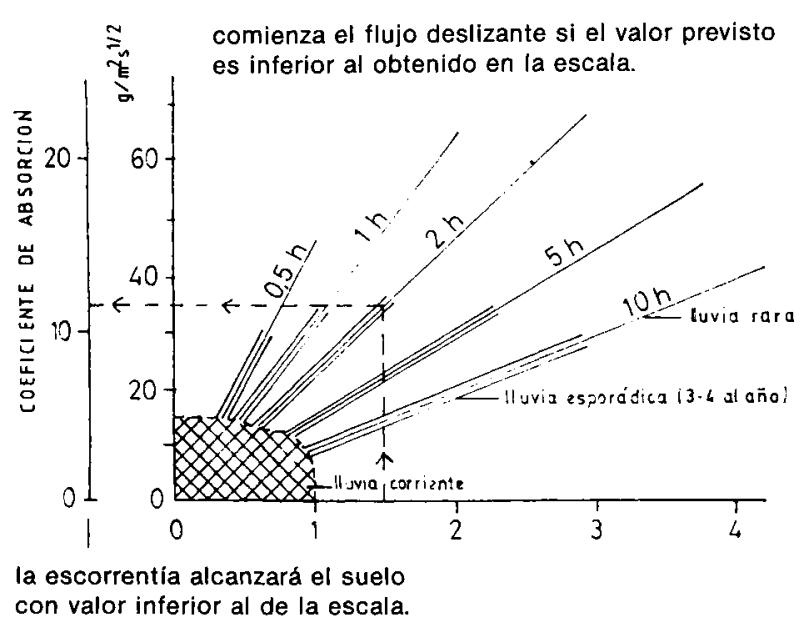

Fig. 3.--Influencia del coeficiente de absorción del material de una fachada sobre el flujo de agua escurrida que resulta de lluvias batientes de distintos tipos $y$ frecuencias (3).

suciedad depositadas. El lavado puede ser sucio o limpio según las condiciones de la superficie afectada, así como del agua escurrida que lo produce. La escorrentía suele separarse en flujos, creados sobre trayectorias preferentes por causa de los obstáculos y de las rugosidades. Ello contribuye a que, si el lavado es sucio, produzca unas marcas, con formas características fácilmente predecibles denominadas escorreduras.

Otra consecuencia de la escorrentía es la de redistribución de la suciedad al depositar nuevamente las partículas arrastradas conforme va siendo absorbida y, especialmente, sobre las trayectorias preferentes.

\subsubsection{Temperatura y vapor de agua}

La influencia de la temperatura es generalmente beneficiosa en relación con la contaminación y, por tanto, con el proceso de ensuciamiento. Su acción fundamental, en los casos de situación atmosférica normal, es la dispersión y dilución de las efusiones contaminan. tes.

La excepción radica en las situaciones en que tienen lugar fenómenos de inversión térmica que impiden dicha acción de saneamiento cuando los efluentes vierten las masas gaseosas por debajo de la capa de inversión.

La temperatura favorece el aumento de la presión de saturación del aire que rodea las fachadas o, lo que es lo mismo, reduce la humedad relativa y, con ello, el riesgo de condensación que contribuye a multiplicar el número de partículas que pueden acceder a la superficie de los paramentos.
Menos clara es su influencia en la modificación de la tasa de agua de lluvia que se deposita sobre las fachadas y su consiguiente deslizamiento hasta la absorción total, si bien, en cualquier caso, hay que convenir en que debe reducir la masa de agua absorbida por la porosidad del material y que, a través del proceso de evaporación, se opone de nuevo al flujo de deposición de las partículas sucias de mayor tamaño.

La existencia de una humedad relativa elevada o de nieblas más o menos persistentes, parece conducir a un incremento notable de la deposición y adhesión de las partículas y, por ello, del ensuciamiento de los materiales porosos poco expuestos al azote del agua-viento.

En esas condiciones, adquieren una pátina de ennegrecimiento más acusada que en situaciones de menor contenido de humedad del aire, para las mismas condiciones de exposición y tasa de generación de contaminación. Esto puede comprobarse fácilmente sin más que comparar la situación de las fachadas de ciudades de la cornisa cantábrica, en relación con otras de zonas del interior o del sur. Valores persistentes superiores al 65 por 100 de humedad relativa comienzan a ser decisivos al respecto.

\subsection{Materiales de revestimiento}

\subsubsection{Tipología de materiales}

Para el estudio del ensuciamiento de fachadas he limitado la casuística de los materiales de revestimiento a los pétreos, naturales y artificiales, en base a su clara predominancia general y, en particular, en la ciudad en que se centra el trabajo. Además, son los más sensibles al fenómeno patológico en cuestión.

Los tipos de materiales se clasifican, a grandes rasgos, en: pétreos naturales, incluyendo las rocas más frecuentes, caliza, arenisca, granito y mármol. Pétreos conglomerados, abarcando los hormigones, cualquiera que sea su proceso de elaboración, y los morteros para revestimientos continuos. El tercer grupo es el de los pétreos cerámicos que incluye las fábricas de ladrillo y los aplacados con losetas.

\subsubsection{Porosidad de los materiales}

El agua de lluvia que incide sobre los paramentos de fachadas puede penetrar en el seno de la porosidad abierta en una cierta magnitud, dependiendo del índice de absorción de agua. Para ello es fundamental la existencia de macroporos, oquedades y defectos de formación del material como son las fisuraciones de la capa superficial. 
La absorción de agua más importante es, sin duda, la que ocurre a través de los poros capilares, caracteristicos de los materiales en cuya formación han intervenido fenómenos de desecación, como sucede con las rocas sedimentarias y todos los pétreos artificiales. La absorción por capilaridad puede evaluarse mediante el coeficiente de succión y también con el factor capilar C - propuesto por Beijer - según la expresión $\mathbf{G}=\mathbf{C} \cdot \boldsymbol{t}^{1 / 2}$, en que $\mathbf{G}$ es la cantidad de agua succionada y $t$ la duración del proceso.

La influencia de la porosidad sobre el ensuciamiento es doble:

- Interviene directamente en la formación del agua de escorrentía, importante en el lavado indirecto y la redistribución de la suciedad, como se analizó con anterioridad. La absorción, medida a través del factor capilar, permite, según los resultados de las experiencias suecas sobre hormigones, predecir el momento de aparición de la lámina discurrente, asi como la extensión de su trayectoria.

- Contribuye al desarrollo de la pátina de suciedad a causa de la penetración de las partículas en el seno de los poros, alveolares o capilares, colmatándolos o adhiriéndose en las proximidades de las embocaduras, lo que puede reforzar la intensidad de la suciedad, además de otros efectos secunda. rios como la posible modificación de la permeabilidad del estrato superficial. Es importante la elevada porosidad inducida en la capa de alteración quimica de la superficie de ciertas rocas naturales, que multiplica la magnitud de la suciedad ya encapsulada.

\subsubsection{Textura superficial de los materiales}

Considero tres tipos de texturas del material caracterizadas tanto por el tamaño de las asperezas como por su respuesta a la deposición y adhesión de las partículas de contaminación y a la distribución del agua de lluvia escurrida. La textura rugosa, más sensible al desarrollo de la pátina pero que suele facilitar un lavado más regular. La lisa, cuya situación intermedia respecto de ambas acciones la hace muy dependiente, en su comportamiento, del tipo de exposición a que se halle sometida la fachada. Y la textura pulimentada, muy favorable para cualquier situación.

\subsubsection{Color de los materiales}

La intensidad con que se perciben las lesiones en las fachadas es directamente proporcional al contraste de color y tonalidad entre los materiales de revestimiento y la pátina de suciedad. En efecto, la suciedad arrai- gada sobre una fachada se hará tanto más evidente cuanto más discontinua y heterogénea aparezca, no sólo con respecto a su localización, sino a su tono o intensidad.

El color constituye un medio de enmascaramiento de la suciedad, si bien no debe utilizarse de manera ais. lada, sino en relación al resto de caracteristicas del material que son las que inducen directamente la virulencia de la pátina.

Otros medios colaterales de enmascaramiento, pero relacionados con el contraste entre el fondo y la suciedad, son el dibujo y algunas formas artificiales de texturación o supratexturación.

\subsubsection{Dureza de los materiales}

La dureza del material interviene pasivamente en el proceso de ensuciamiento, a través de los tipos de choques de las partículas de suciedad, que causan el que éstas reboten hacia el exterior o bien queden atrapadas sobre la superficie del material, según el balance de las energías de incidencia y de rechazo, asi como del tamaño de las partículas.

Tanto como la dureza intrínseca del material influye la rugosidad y porosidad abierta de su superficie, modificando la fenomenología de los choques.

También se producen las mismas situaciones con el choque de las gotas del agua de lluvia contra los paramentos, pudiendo ser o no captadas por el material de soporte, siendo inmediatamente absorbidas por él, o constituyendo el flujo discurrente.

\subsection{Organización general de las fachadas}

\subsubsection{Formas y proporciones de las fachadas}

La influencia de la forma en el comportamiento de las fachadas ante el ensuciamiento es poco conocida, seguramente porque la escasez de ejemplos de tipos alejados de la usual forma rectangular la convierten en poco relevante. Dicha forma rectangular, poco aerodinámica, ha sido la más analizada, en combinación con las proporciones, en los experimentos sobre modelos $y$ en túneles de viento.

Las proporciones de las fachadas afectan directamente al modo de incidencia del viento que se acerca hacia ellas, en régimen de franja límite, es decir, de gradiente de velocidad debido al rozamiento con los obstáculos, modificando sus trayectorias para tratar de esquivarlo. La proporción definirá la magnitud de las zonas que recibirán un potencial lavado. 


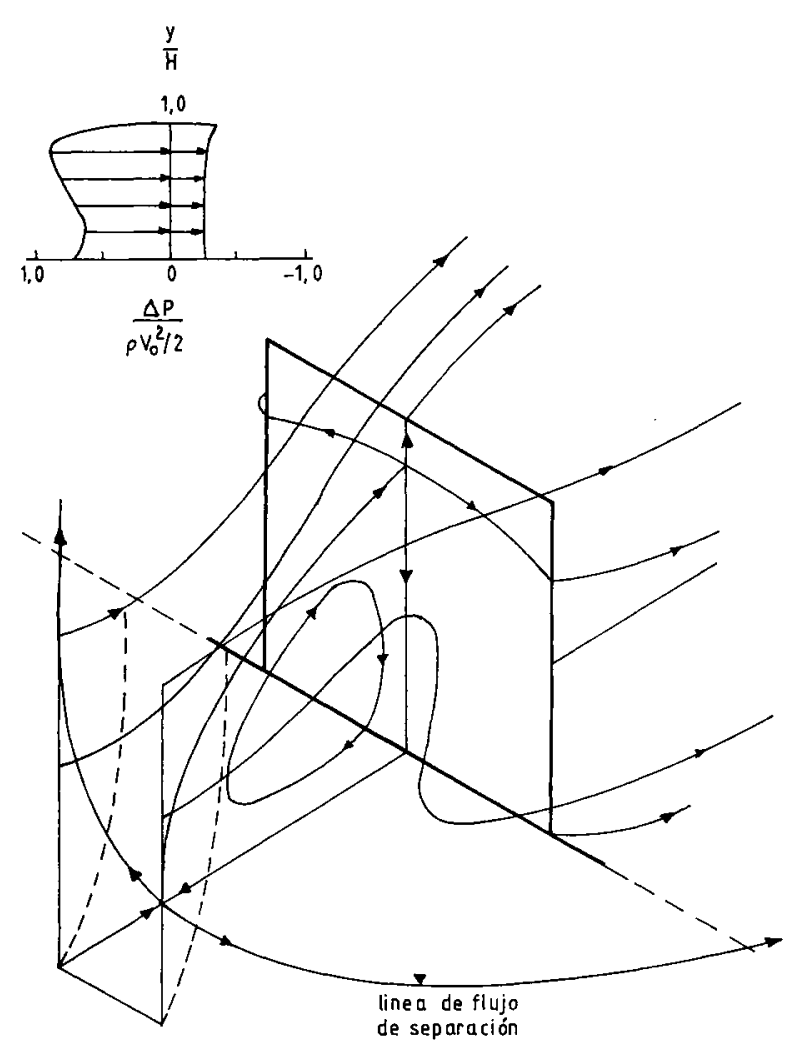

Fig. 4.-Trayectorias y empuje del viento sobre una fachada de proporción cuadrada.

En los edificios exentos, en general en todos, el efecto de la protección o abrigo por otros obstáculós supone la disminución de la presión dinámica en coronación, acumulándose las líneas de flujo en una banda más estrecha junto al borde, y un consiguiente aumento de la zona de remolino de presión inferior y constante. Las mismas consideraciones serian aplicables a las fachadas posterior y laterales (Fig. 4).

La manera en que las fachadas se ensucian parece claramente relacionada con sus proporciones a la vez que con su nivel de exposición, dependiente tanto de la orientación frente a las corrientes de aire, como a la protección antes mencionada.

Lo que permite averiguar la influencia de la forma es la distribución de las líneas de flujo de aire que encuentra en su camino al edificio, así como la distribución de los gradientes no de presión (y succión) ejercidos sobre la superficie de las fachadas. Con ello podrán predecirse los transportes de partículas hacia los paramentos, así como la acción de limpieza debida al simple impulso del aire. Lo mismo cabe decir para el agua de lluvia, por su estrecha relación con el tipo de acción del viento.

\subsubsection{Composición general de la fachada}

La composición general de la fachada resulta vital para predecir el resultado de las acciones de ensucia- miento y lavado que ocurren sobre ella. El tamaño y la disposición de los planos de fábrica y los de acristalamiento suponen unas implicaciones claramente definidas sobre los modelos resultantes.

Quizás el aspecto más importante sea el referente a la inclinación de los planos: efectivamente, si la inclinación es con la horizontal, influirá decisivamente en la cantidad de partículas que se depositen por mecanismos gravitatorios, a la vez que determinará la cantidad de agua de lluvia directa que pueden alcanzar esos planos. Pero, además, las implicaciones se extienden a la acción del agua escurrida, pues dichos planos inclinados no se hallan aislados, sino que son precedidos y seguidos por otros, con los que forman ciertos ángulos diedros, o bien constituyen superficies curvas, afectando al tipo de lavado y a la formación de manchas aisladas de suciedad (Fig. 5).

Si la inclinación de los planos es con la vertical, los efectos inducidos se relacionan con la orientación, exposición y abrigo, surgiendo también los diedros verticales capaces de modificar el volumen y forma de las trayectorias de la escorrentía según se trata de rincones o esquinas (Fig. 6, pág. siguiente).

El segundo factor compositivo que afecta a la formación de las suciedades es la disposición relativa de los planos macizos, es decir su colocación en un plano úni-
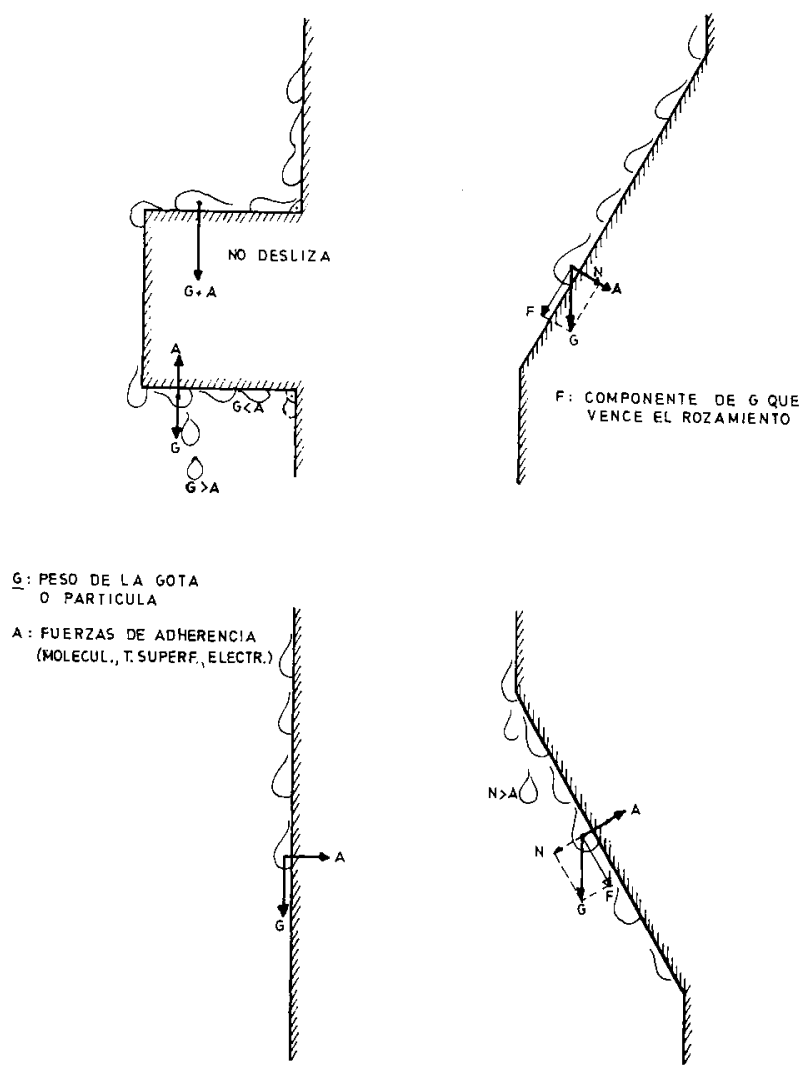

Fig. 5.-Desplazamiento del agua escurrida según la inclinación de los planos. 


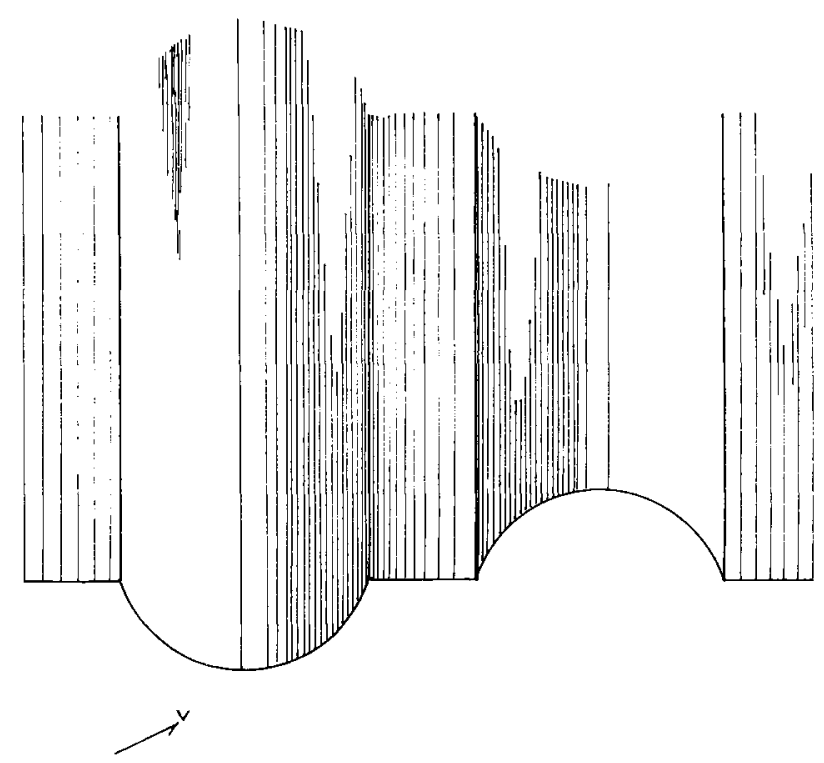

Situación sobre planos curvos verticales cóncavos y convexos.
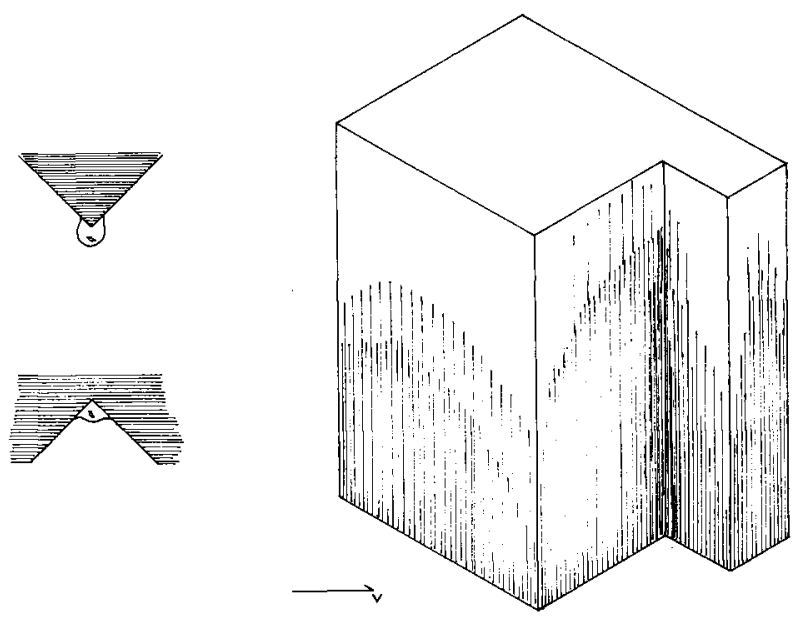

Modificación del lavado por efecto del rozamiento del agua escurrida: efectos de arista y rincón. Parábolas de suciedad características de fachadas de edificaciones exentas.

Fig. 6.

co general, o la aparición de unos planos avanzados o volados, esto es, situados a desnivel. Ello será fuente de efectos inducidos de abrigo, lavado y los derivados de la aparición de diedros verticales y los consiguientes efectos de arista y de rincón. Las posibilidades de solucionar las fachadas con lienzos no coplanarios son amplias, lo mismo que los modelos de ensuciamiento resultantes. Como casos particulares se citan los de balcones y miradores exentos.

Cabe constatar, también, la influencia que ejercen las diversas formas posibles de los huecos en la formación de las suciedades. No obstante, este factor ha de considerarse forzosamente menor, si se compara con los analizados hasta el momento, siendo su actuación un aporte más al conjunto de fenómenos implicados en el proceso global.

\subsubsection{Textura general de la fachada}

Los principales componentes de la textura de las fachadas son: a) ornamentales, como los estriados y relieves, sobresalientes o rehundidos; b) juntas, de fábri$\mathrm{ca}$, de montaje o funcionales; c) singulares decorativos o de drenajes, como impostas, cornisas, vierteaguas y gárgolas.

Todos los elementos componentes del relieve general de la fachada, al suponer discontinuidades sobre la lisura de un paramento, constituyen fuentes de acumulación de suciedad, proporcionando plataformas más o menos grandes y frecuentemente abrigadas.

Aparte de la acumulación de suciedad, las discontinuidades son capaces de acumular agua de lluvia directa que es inmediatamente arrojada hacia las superficies inmediatas inferiores. En ciertas condiciones dichos vertidos pueden ser muy sucios y destacados o bien pueden lavar irregularmente otros planos más sucios, ambos efectos no deseados (Fig. 7).

Entre las consecuencias positivas cabe destacar también dos: la primera seria la de crear una macrotextura que, si es continua en toda la fachada o en grandes paños, opera distribuyendo uniformemente el agua de lluvia escurrida. Si ésta es suficiente, el lavado general será aceptable y beneficioso.

La misma composición ornamental sirve, en ciertos casos, como factor de enmascaramiento de la pátina de suciedad y de lavados irregulares débiles, al crear unos efectos visuales de luz y sombra, de rayado o dibujo que resultan dominantes sobre la apariencia de las suciedades (Fig. 8).
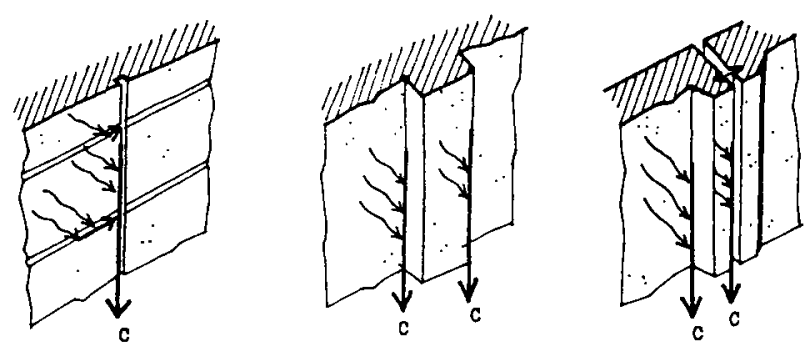

Efecto canalizador de acanaladuras y molduras diversas (7).
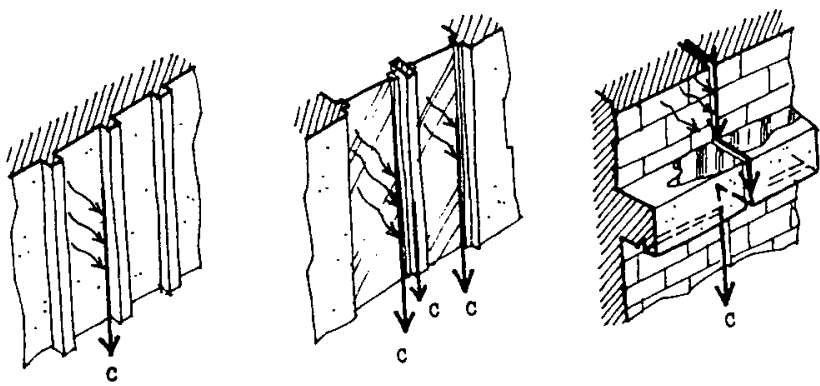

Fig. 7 


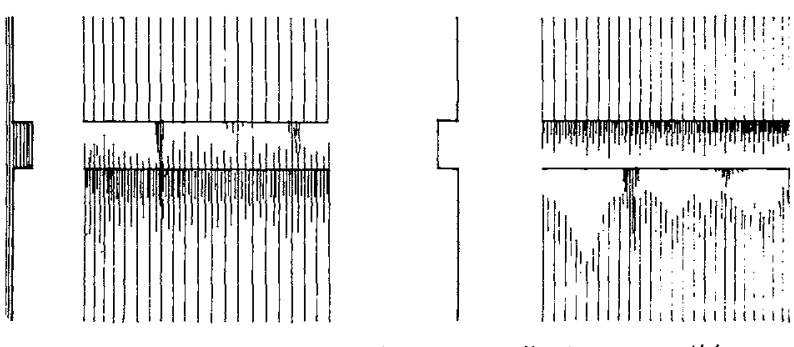

Efectos de la existencia de impostas salientes y remetidas.

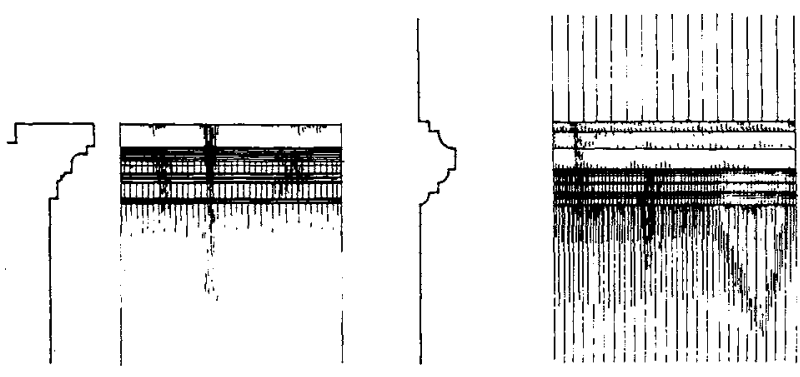

Efectos de la cornisa e imposta molduradas sobre el ensuciamiento.

Fig. 8.

\section{2.a PARTE: ESTUDIO DE UNA MUESTRA DE FACHADAS}

\section{ANÁLISIS DEL MEDIO ATMOSFÉRICO DE VALLADOLID}

\section{1. Áreas de contaminación atmostérica}

La correlación de los datos de emisión de humos con el proceso de ensuciamiento y su evolución, resulta prácticamente imposible a falta de una infraestructura de control de ennegrecimiento de fachadas según la escala de Bacharach, graduada de 0 a 9 , para la determinación de la opacidad de los gases de combus. tión.

En razón a lo anterior he optado por utilizar como parámetro de grado de contaminación un factor de $\mathrm{O}$ a 3 , que supone cuatro niveles tipo, en relación al impacto de la contaminación en las áreas de influencias de las estaciones de medición, aludidos en el informe del año 1985 del Ayuntamiento de Valladolid:
0 - Nivel nulo o bajo.
1 - Nivel moderado.
2 - Nivel medio.
3- Nivel elevado.

De este modo, cada edificio, y por consiguiente sus fachadas, tendrán asignado un valor del factor de contaminación en función de su inclusión en una de las áreas de influencia de las estaciones captadoras. Dicho sistema simplificado establece una valoración cualitativa, más que cuantitativa, del grado de influencia de los humos negros sobre las fachadas particulares, para lo que se requeririan medios y tiempo fuera del alcance de esta investigación.

\subsection{Influencia del viento y factor de protección}

Los valores de velocidad escalar (intensidad del vien. to asociada a su frecuencia), pueden dar indicios so. bre la escasa capacidad del viento en el arrastre de partículas depositadas, sobre todo si ya comenzó el proceso de su adhesión físico-química al soporte.

No sucede lo mismo con el viento asociado a la lluvia, como se verá en el siguiente apartado, puesto que los sucesos de viento superior a $4 \mathrm{~km} / \mathrm{h}$, capaces ya de producir una cierta inclinación de la trayectoria de caída del agua, suman casi el 63 por 100 de los totales.

En otro orden de cosas, la contribución del viento en la dispersión de contaminantes es un punto fundamen. tal. Puede relacionarse estrechamente el nivel de partículas en suspensión con el tráfico rodado urbano, que sucede en superficie y está, por consiguiente, menos sujeto a la influencia del viento de cierta intensidad, si bien el mismo tráfico causa turbulencias de aire ca. paces de remover y elevar, en alguna medida, los flujos de contaminación. Cobran bastante más importancia las configuraciones urbanisticas en que se favorecen y dificultan dichas turbulencias y las corrientes de aire embocadas por las calles, influyendo poderosa. mente la orientación a los vientos dominantes y reinantes (Fig. 9).

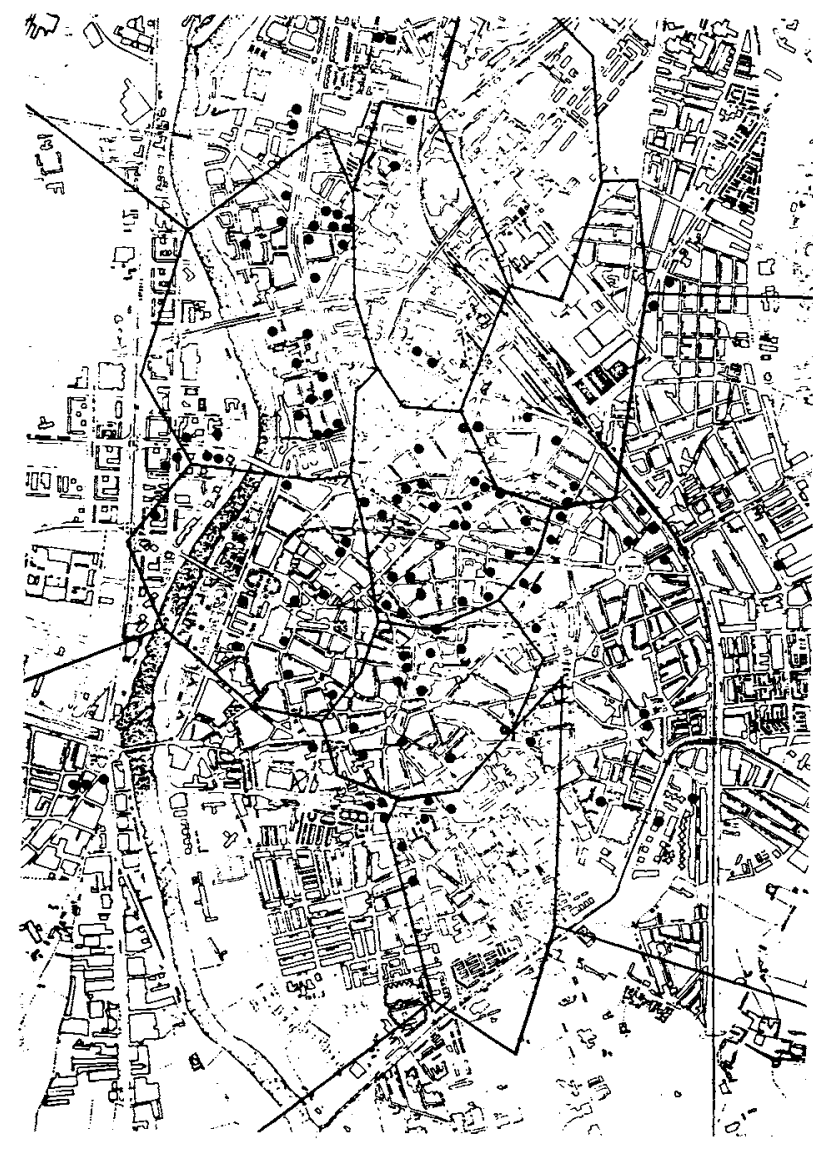

Fig. 9 
Conviene recordar, de todos modos, la contribución de las calderas de combustión que vierten en nivel de cubiertas o superior, pero en que el tamaño de partículas y otros aspectos adicionales, como nieblas o inversiones térmicas, conducen a una deposición gravitatoria casi inmediata, salvo que las inmisiones se produzcan con vientos de intensidad media o alta, cuya frecuencia global no alcanza el 30 por 100 de la total.

La acción que desarrolla el viento aislado o asociado con el agua se encuentra muy relacionada con el perfil del terreno y, en nuestro caso, con el de la ciudad objeto del estudio, cuya morfologia urbanistica es determinante del comportamiento de los flujos de aire, sabiendo que los edificios actúan de pantalla interpuesta entre otros, lo mismo que un frente de calle sobre el opuesto. Con independencia de que las corrientes dominantes pueden operar en realidad oblicuamente (que seria la circunstancia más general) 0 , incluso, paralelamente, como sucede en aquellas calles que son auténticas tuberías conductoras de las corrientes de aire.

Dicha situación debe ser contemplada también. $Y$ ante la imposibilidad de analizar el flujo mismo de aire, dada su variabilidad y dificultad de medida, se recurre a la simplificación de considerar cada fachada como un caso particular y suponer que a ella accede una cierta cantidad de flujo controlada por el efecto de abrigo de los edificios enfrentados, y cuantificado mediante un factor de protección, corrector de la magnitud del viento que accederia normalmente si el edificio estuviera totalmente aislado.

El factor de protección adopta cuatro grados: $V, X, Y$ y $Z$, según que la fachada esté muy abrigada, medianamente abrigada, poco protegida o totalmente desprotegida, respectivamente.

\subsection{Influencia de las precipitaciones}

Las Iluvias más importantes, esto es, las más intensas, se producen raramente y concentradas en su mayoría en los meses de verano (junio-agosto).

Por ello, a los efectos del presente trabajo, resulta fácil pensar que en nuestra ciudad, para situaciones de viento en calma 0 de muy poca importancia $(0 \mathrm{a} 1 \mathrm{~m} / \mathrm{s})$, las precipitaciones de lluvia serán verticales o muy poco inclinadas, por lo que su efecto básico será el saneamiento atmosférico realizado prioritariamente en invierno y primavera, en que se concentran las lluvias aunque sean las de menor intensidad. Otra consecuencia de ese tipo de lluvias es el lavado casi exclusivo de las superficies horizontales que se encuentran en saledizo o en retranqueo de poca magnitud (por ejemplo alféizares, impostas, etc.), independientemente del lavado producido por el escurrimiento del agua acumulada en dichas plataformas.

\subsection{Factor de exposición: acción del "viento-lluvia"}

El factor de exposición es el parámetro fundamental en la valoración de la acción del par lluvia viento. Se obtiene como suma de los productos de la velocidad del viento por la cantidad o altura de lluvia caída, para cada dirección considerada, teniendo en cuenta que para una determinada orientación de fachada fluye sobre ella viento de componente perpendicular al que hay que sumar las incidencias de las seis direcciones correlativas que tienen componente en dicha dirección y que, por consiguiente, se obtendrán multiplicando el valor de velocidad ortogonal por los cosenos de $22,5^{\circ}$, $45^{\circ}$ y $77,5^{\circ}$ (1).

Los diagramas que representan la distribución de los valores del factor de exposición, según la rosa de los vientos, indican la capacidad de una fachada situada en una determinada orientación, para ser lavada por la Iluvia, en función de la cantidad de precipitación y de la velocidad del viento que sopla contra ella. Siguiendo la proposición del estudio francés sobre las suciedades (1), he dividido la rosa de los vientos en varios sectores, asignando a cada uno de ellos un determinado nivel de exposición tal como se representa en la figura 10.

Así pues durante medio año (marzo-agosto) hay que considerar el lavado por agua de lluvia batiente y escurrida, mientras que durante el resto del año la acción de limpieza correrá a cargo casi exclusivamente de la escorrentía que estará dotada de menor velocidad, pues el aporte es lento, continuo y poco intenso. Sin embargo, esto no debería oponerse a que los arrastres y erosiones produzcan resultados importantes, si recordamos que la frecuencia y la magnitud de los lavados suelen predominar sobre las acciones de depósito y adhesión, siempre que la lluvia sea capaz de alcanzar las superficies de las fachadas.

La acción de limpieza atmosférica se produce con ocurrencia simultánea de viento en calma y lluvia; o sin lluvia pero con vientos importantes y, evidentemente, cuando suceden a la vez ambos fenómenos. En la ciudad castellana hay dos periodos potencialmente peligrosos: otoño (septiembre y octubre), con bajo volumen de precipitaciones de mediana intensidad, baja velocidad de viento y tráfico incrementado por los retornos de vacaciones y reanudación de actividades. También en los primeros meses de invierno (noviembre-enero), en que se incrementa el volumen de contaminación debida a la combustión de calderas de calefacción, y que se reparte en etapas ciclónicas con alta pluviosidad de 

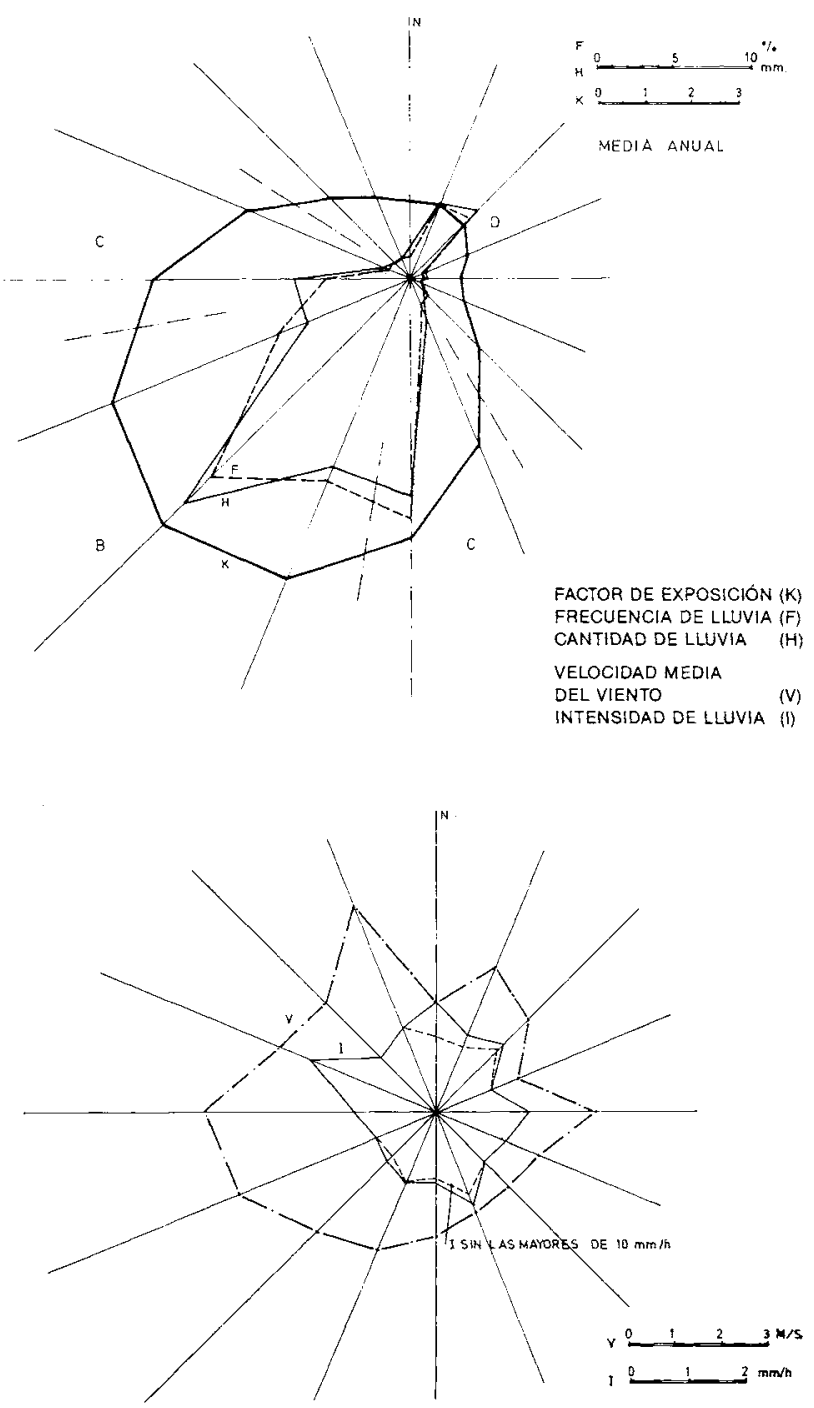

- nivel A: factor de expos. $>9$ = fachada muy expuesta

- nivel B: factor $9 \geq f \geq 6$ = fachada expuesta;

- nivel C: factor $6 \geq f \geq 3=$ medianamente expuesta;

- nivel D: factor menor que 3 = fachada poco expuesta

Fig. 10

baja intensidad y viento medio, en las que funciona un adecuado saneamiento, y en etapas anticiclónicas, muchas veces coincidentes con nieblas persistentes e inversiones térmicas carentes de lluvia y viento, y muy activas en cuanto a la tasa de deposición y adhesión, por el incremento de la humedad relativa y las condensaciones.

\subsection{Influencia de la humedad relativa}

Los datos de humedad relativa indican que los meses de noviembre a febrero y, ocasionalmente, octubre a marzo, poseen indices superiores al 65 por 100 , lo que aumenta la potencialidad de la deposición de partículas, de por si elevada en esta época invernal por las razones expuestas anteriormente.
Parece aceptarse como norma general la preponderancia de los valores de humedad relativa, con la conclusión de que en invierno se acusa la tendencia a la condensación que favorece la deposición/adhesión, mientras que la evaporación lo es en los meses centrales del año, oponiéndose teóricamente al ensuciamiento o, al menos, dificultándolo.

En otro orden de cosas, la abundancia de vapor de agua en la atmósfera, coincidente con las nieblas persistentes, genera una elevada tasa de nucleación de particulas de polvo que, a su vez, incrementan la facilidad de condensación del vapor y su sedimentación en las lluvias inapreciables con origen en las mismas nieblas.

\section{FICHADO DE UNA MUESTRA DE FACHADAS}

\subsection{Criterios de selección de la muestra}

1. Percepción de las suciedades: la selección debia recoger ejemplos de fachadas afectadas por la lesión y que ésta fuera apreciable o perceptible por un observador medio situado en el nivel de la calle a la que se abrieran los paramentos. De ello derivaba, simultáneamente, el que la imagen del ensuciamiento pudiera ser captada fotográficamente para facilitar el posterior análisis de los datos.

2. Nivel de contaminación: parecia natural que una situación originada fundamentalmente por las particulas de polución atmosférica, contemplase los casos en función de los niveles de contaminación. Asi pues, los ejemplos se obtendrian de las zonas de influencia de las estaciones de captación, a su vez repartidas para cubrir todo el área metropolitana.

3. Distribución geográfica: era importante cubrir toda la extensión de la ciudad, para lo que podía utilizarse cualquier zonificación urbanística. Sin embargo, opté por aunar este criterio con el anterior, ya que la zonificación por áreas de influencia de captadores cubre la total extensión de la ciudad.

Con todo, consideré ya de antemano, como un hecho importante, la previsión de una distribución no uniforme de los casos por el área urbana, debido a las siguientes razones: disminución del indice de contaminación y, consiguientemente, de la virulencia del ensuciamiento conforme aumenta la distancia al centro urbano. La otra razón era la disminución de variables tipológicas edificatorias, principalmente las referentes a materiales y a composición de las fachadas, en razón del incremento de la juventud y degradación caracteristicas de los edificios, directamente proporcional a su proximidad a los barrios periféricos. 
4. Tipología edificatoria: únicamente existia la obligación de restringir la muestra a las fachadas revestidas con materiales pétreos, ya que el resto, aunque posiblemente afectado por las lesiones, caía fuera del ámbito del trabajo. Al margen de este pie forzado, interesaba diversificar al máximo la muestra en relación al uso, altura y antigüedad de los edificios, asi como a la composición, ornamentación y, especialmente, tipologia de los materiales de revestimiento de sus fachadas.

\subsection{Toma de datos}

Realizada in situ, tras la selección de los casos, consistia en cubrir una parte de la ficha, especialmente la de datos de identificación, los referentes a materiales y morfologia de la fachada, asi como los de sintomas de la lesión. Es decir, todos aquellos datos que eran perceptibles a la simple vista de las fachadas del edificio y que, aunque pudieran obtenerse de la información gráfica, requerian preferentemente la observación directa. Otros, como el grado de abrigo o protección, el uso y, en general, el color de los materiales y de las suciedades, precisaban obligadamente de dicha labor de campo.

\subsection{Cumplimentación de las fichas}

Los datos recogidos sobre el terreno eran completados posteriormente con aquellos que necesitaban algún tratamiento o medición, tales como el nivel de contaminación, el factor de exposición, la proporción de las fachadas, a la vez que se procedía a un repaso general sobre las fotografías, realizando los ajustes apuntados en el apartado de selección.

Del mismo modo, a la vista de todos los datos, y tras una etapa de reflexión y de interrelación con los presupuestos teóricos, se acometía el análisis en sus tres apartados de causas, observaciones de diagnóstico y calificación de las lesiones.

\subsection{Fichas de la muestra}

Como resultado del proceso explicado en los apartados precedentes, se elaboraron las 125 fichas de la muestra de edificios escogidos según los criterios anteriormente expuestos y que caracterizarán, en lo siguiente, los modelos usuales de comportamiento de las fachadas frente a las suciedades.

\subsection{Calificación de las lesiones}

Es el parámetro que permite cualificar la magnitud del ensuciamiento, objetivado de la siguiente manera:

Leve (I): si se datan manchas leves, aisladas y localizadas, o pátina regular muy poco destacada, de color gris (c) Consejo Superior de Investigaciones Científicas Licencia Creative Commons 3.0 España (by-nc) claro, de forma regular, ocupando total o parcialmente una fachada. Suele caracterizar los edificios de reciente construcción, los de zonas sin tráfico rodado y los de diseño de fachada y combinación de materiales que impide la formación de suciedades, al menos a medio pla. zo.

Normal (n): definida por pátinas irregulares poco intensas, con frecuentes marcas de lavado, ubicadas en la mitad superior de la fachada, y por pátinas regulares poco intensas en los pisos bajos. También incluyo en esta calificación los casos frecuentes de fachadas cuyos materiales y colores enmascaran parcialmente la suciedad, siendo por lo común sólo apreciables manchas oscuras alternando con lavados y escorreduras en los cantos de forjados (Fig. 11).

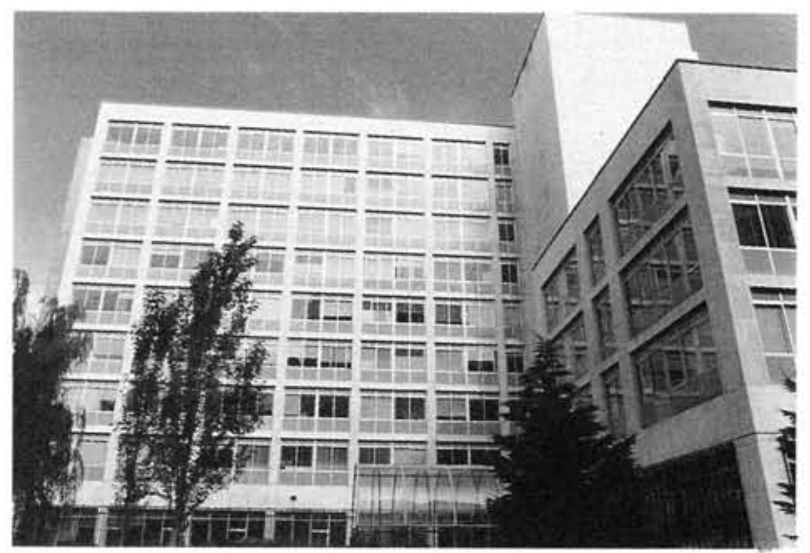

Fig. 11

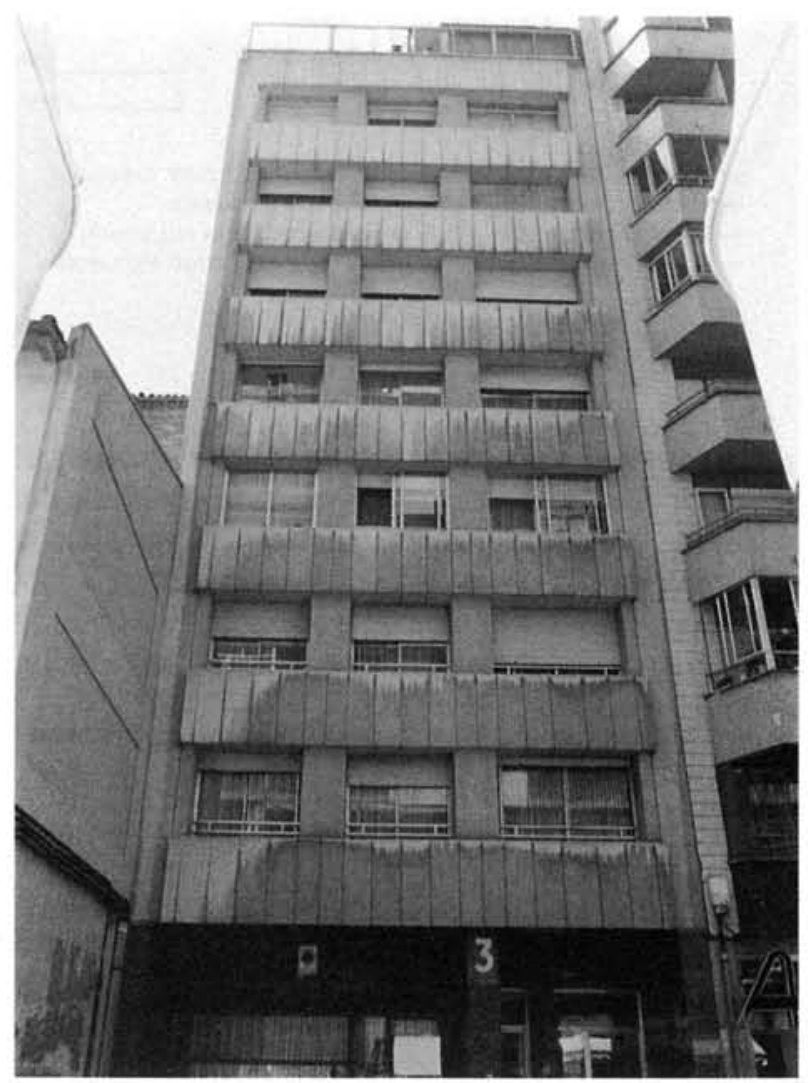

Fig. 12

http://informesdelaconstruccion.revistas.csic.es 


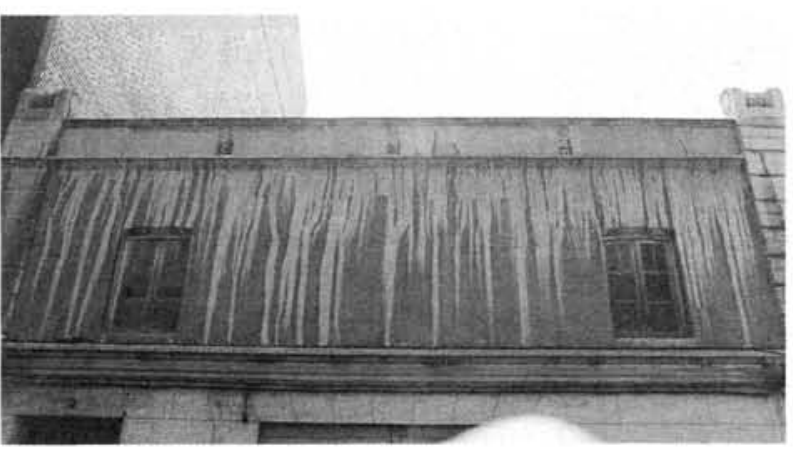

Fig. 13

Intensa (i): caracteriza a las fachadas con pátina de cierta intensidad y fuerte gradación, típica de edificios aislados en áreas de elevado nivel de contaminación. 0 bien cuando presentan zonas de lavados muy desta- cados por su forma irregular o de flecos o dientes de sierra. Incluyo también las que poseen pátinas regulares no intensas pero afectadas por escorreduras aisladas pero destacadas (Fig. 12).

Grave (g): comprenderia a buena parte de los edificios históricos, revestidos por lo general con silleria de piedra, que han desarrollado a lo largo de centurias una fuerte pátina (en realidad costra de sulfatación oscura o negra) bastante regular pero surcada de bandas de lavado muy irregulares y blancas, contrastando fuertemente con el resto sucio. También se incluyen aquellos edificios más modernos cuyas fachadas sufren abundantes manchas por escorreduras sucias o con existencia de todo tipo de sintomas muy irregularmente distribuidos, y en que los fuertes contrastes acentúan la sensación de suciedad (Fig. 13).

FICHA 018/a EDIFICIO: Iglesia de San Miguel DIRECCION: Cl. San Ignacio

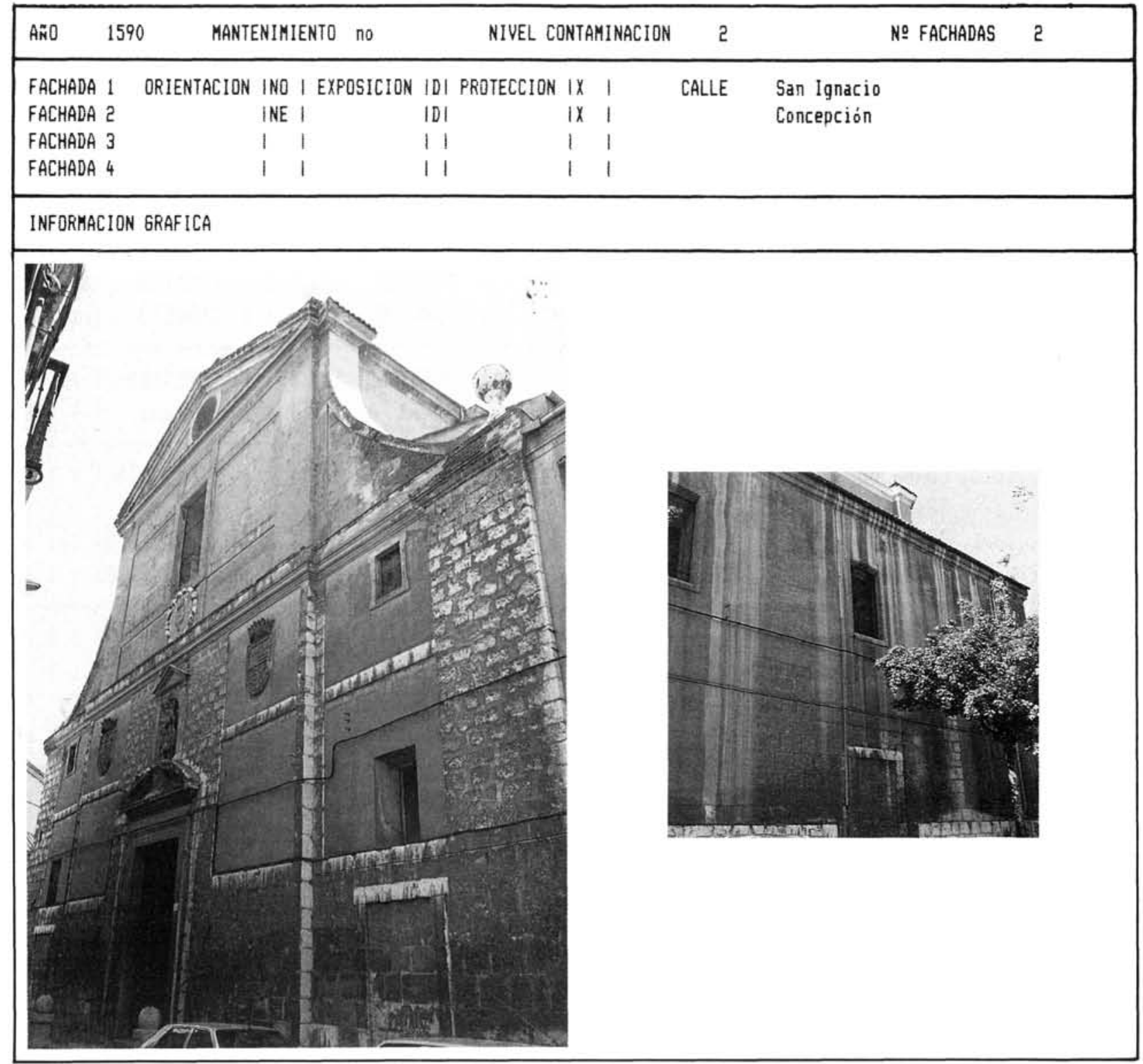




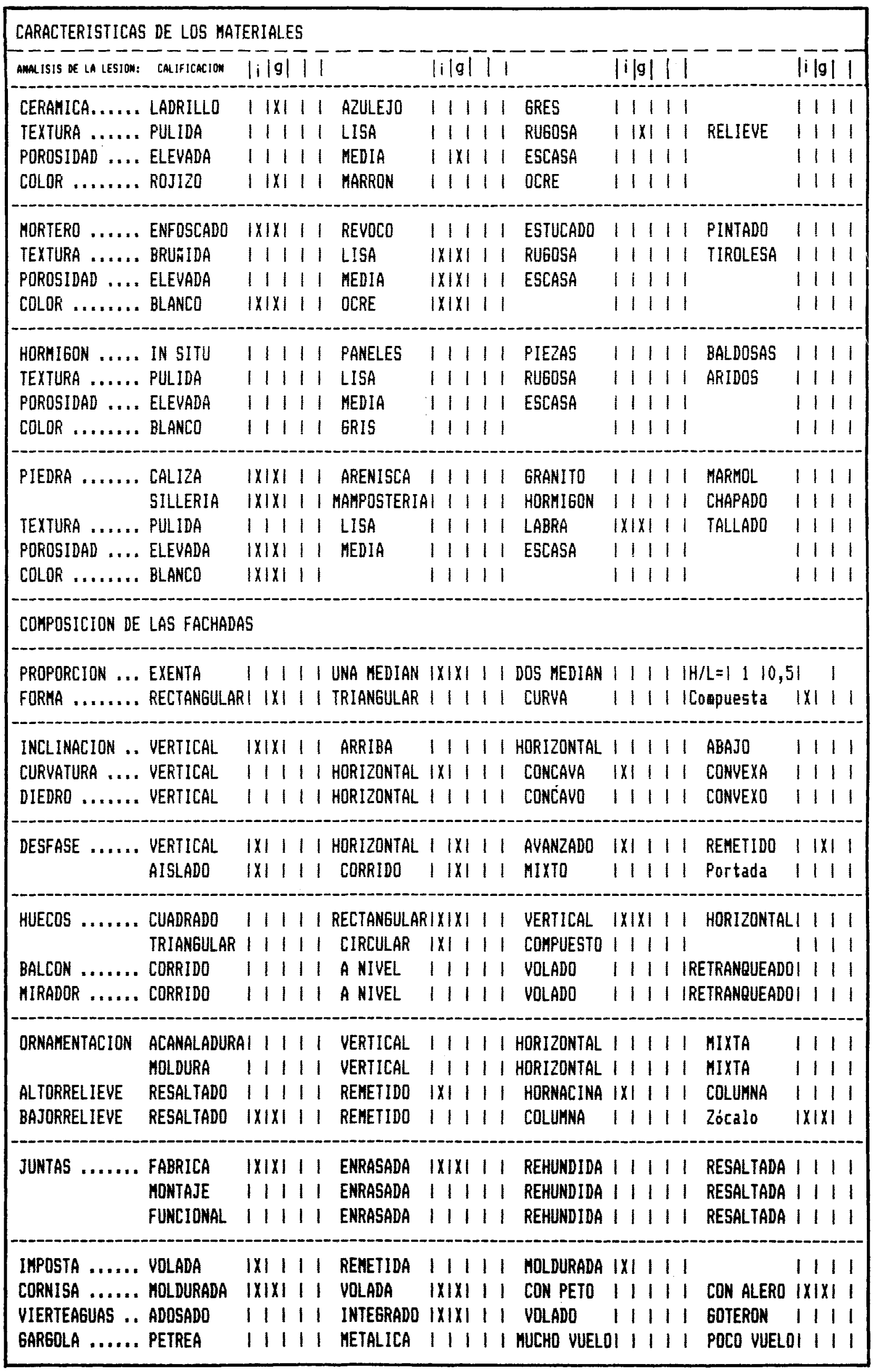


FICHA 018/C EDIFICIO: Iglesia de San Miguel DIRECCIÓN: Cl. San Ignacio

\begin{tabular}{|c|c|c|c|}
\hline ANALISIS DE LA LESION: CALIFICACION & $|i| g|| 1$ & $|i| g|| \mid$ & $|i| g \mid 1$ \\
\hline \multicolumn{4}{|l|}{ ANALISIS DE LA LESION: ETIOLOGIA } \\
\hline $\begin{array}{c}\text { SINTOMAS } \ldots \text { FATINA GEGULAR } \\
\text { LAVADOS }\end{array}$ & $\begin{array}{lll}|X| X \mid & \text { I } & \text { PATINA IRREGULAR } \\
|X| X \mid & \text { I I MANCHAS AISLADAS }\end{array}$ & $\begin{array}{lllll}1 & 1 & 1 & 1 & 1 \\
1 & 1 & 1 & 1 & 1\end{array}$ & $\begin{array}{lll}|x| x \mid & 1 \\
1 & 1 & 1\end{array}$ \\
\hline $\begin{aligned} \text { UBICACION } \ldots & \text { GENERALIZADA } \\
& \text { PLANTAS INFEFIORES } \\
& \text { CAPIALZADOS } \\
& \text { JUNTAS }\end{aligned}$ & $\begin{array}{llllll}|X| X \mid & 1 & 1 & 1 & \text { CORNISA } \\
1 & 1 & 1 & 1 & 1 & \text { ENTREPANOS HORIZONTALES } \\
1 & 1 & 1 & 1 & 1 & \text { ANTEPECHOS } \\
1 & 1 & 1 & 1 & 1\end{array}$ & $\begin{array}{llllll}1 & 1 & 1 & 1 & 1 & \text { PLANTAS ALTAS } \\
1 & 1 & 1 & 1 & 1 \\
1 & 1 & 1 & 1 & 1 \\
1 & 1 & 1 & \text { RELIREPANOS UEV } \\
1 & 1 & 1 & 1 & 1\end{array}$ & $\begin{array}{llll}1 & 1 & 1 & 1 \\
1 & 1 & 1 & 1 \\
1 & 1 & 1 & 1 \\
1 & 1 & 1 & 1\end{array}$ \\
\hline $\begin{aligned} \text { EXTENSION } \ldots & \text { TOTALIDAD DE LA FACHADA } \\
& \text { OCUPANDO UN ELEMENTO }\end{aligned}$ & 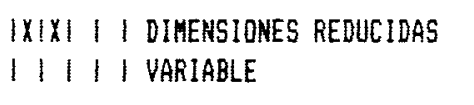 & 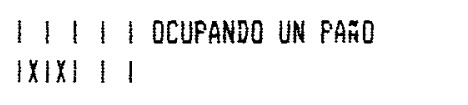 & $\begin{array}{llll}1 & 1 & 1 & 1 \\
1 & 1 & 1 & 1\end{array}$ \\
\hline $\begin{aligned} \text { FORMA } \ldots \ldots \ldots & \text { AREA REGULAR } \\
& \text { FLECOS }\end{aligned}$ & 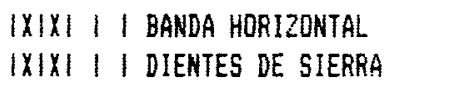 & $\begin{array}{l}|X| X|| \mid \text { BANDA VERTICAL } \\
|||| \mid \text { Manchas irregulares }\end{array}$ & $\begin{array}{l}|x| x \mid 1 \\
|x| x \mid 1\end{array}$ \\
\hline $\begin{aligned} \text { COLOR } \ldots . . . . . ~ & \text { NEGRO } \\
& \text { PARDUUZCO }\end{aligned}$ & $\begin{array}{llll}|X| X \mid & 1 & \text { GRIS OBSCURO } \\
1 & \mid 1 & \mid & \mid \\
\end{array}$ & $\begin{array}{lll}|X| X \mid & \mid & 1 \\
|X| X \mid & \mid & 1\end{array}$ & $\begin{array}{l}|x| x \mid 1 \\
1111\end{array}$ \\
\hline ANALISIS DE LA LESION: DIAENOSTICO & & & \\
\hline $\begin{aligned} \text { CAUSAS } \ldots . . . & \text { ELEVADA CONTAKINACION } \\
& \text { CONTRASTE DE COLOR } \\
& \text { LLUVIA BATIENTE } \\
& \text { TURBULENCIA LOCALIZADA } \\
& \text { DESCENSO VELOCIDAD LAMINA } \\
& \text { ABRIGO POR REHUNDIDO } \\
& \text { ANTIGÜEDAD SIN MANTENIM. }\end{aligned}$ & 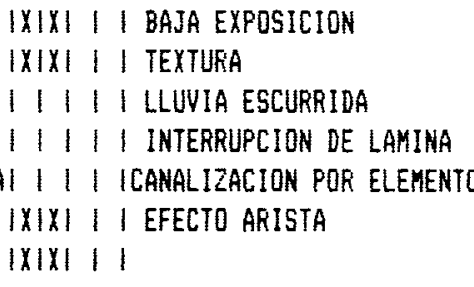 & 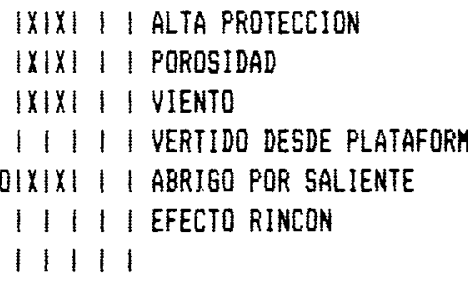 & 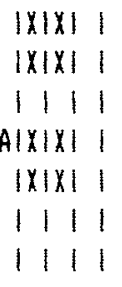 \\
\hline
\end{tabular}

ANALISIS DE LA LESION: DBSERVACIONES DE DIAENOSTICO

Se observa pátina muy desarrollada, principalmente sobre la piedra que, en ausencia de mantenimiento, ha adquirido costra de alteración gris o negra según la altura y el grado de abrigo por el edificio de enfrente o por otros elementos de la misma fachada. Contrasta mucho con todas aquellas partes muy blancas por disolución continuada de la capa superficial a expensas del agua de lluvia escurrida. Tal ocurre sobre las impostas, frontones recercados y zócalos, en que el agua alcanza las plataformas y rebosa para verterse con diferente alcance según el volumen de escorrentia. Ejemplo destacable es el de la cara lateral del desfase de la portada, situado a barlovento (SO), siendo azotado por el viento más frecuente canalizado por la calle.

Sobre los morteros, cuyo comportamiento es mejor gracias a su textura, porosidad y coloración, las manchas son debidas, principalmente, a depósitos muy abrigados por elementos salientes (cornisa, recercos, imposta) y a pequeñas escorreduras desde las plataformas horizontales a lo largo de la anchura de cornisa, impostas y antepechos.

Sin embargo, en la fachada a NE aparecen escorreduras muy importantes y destacadas de agua limpia que producen lavados extendidos a toda la altura de la fachada, y que fienen su origen en vertidos puntuales desde la cubierta por la inexistencia de canalón y la escasez de vuelo de la cornisa.

\section{RESULTADOS DEL MUESTREO: TEXTURA DE LOS MATERIALES DE REVESTIMIENTO}

La evaluación de las fichas se efectuó mediante tablas que reflejan resultados porcentuales referidos a las fachadas afectadas por un determinado parámetro. En ellas se dan también los valores medios de referencia (en negrita) de las fachadas para cada tipo de calificación, lo que permite observar $(t,-,=$, etc.) las des- de variable); $M$ (muestra de 233 fachadas). (Ver cuadro en la pág. siguiente).

Los valores globales parecen responder perfectamente a las previsiones, con porcentajes de dos tercios para la textura rugosa, 27 por 100 para la lisa, y sólo 6 por ciento de la pulimentada. No obstante, conviene recordar que, con independencia de la ocurrencia de aparición de suciedades, las soluciones de revestimientos 


\begin{tabular}{|c|c|c|c|c|c|}
\hline $\begin{array}{l}\text { PARAMETRO } \\
\text { =:=:=:=:=:=:=:= }\end{array}$ & $======$ & 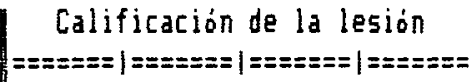 & $\begin{array}{l}\text { PARAMETRO } \\
======== \pm===\end{array}$ & & $\begin{array}{l}\text { Calificación de la lesi } \\
===|===|===|===|===1===1==\end{array}$ \\
\hline IEXIURA & 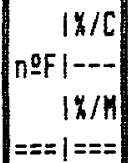 & 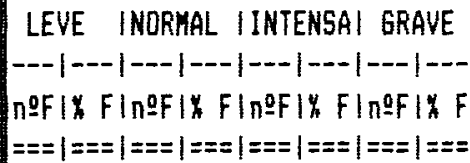 & Lisa & $\begin{array}{r}127 \\
132 \mid=- \\
152 \\
-1---\end{array}$ & 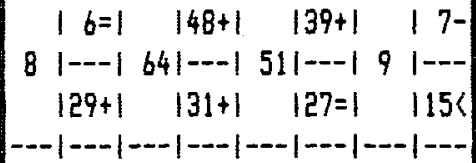 \\
\hline Rugosa & $\begin{array}{r}167 \\
3251- \\
191 \\
\hdashline-1\end{array}$ & $\begin{array}{rrr}15-1 \quad 142-1 \quad 138=1 \quad 115+ \\
181--11351--11231--1491-- \\
164-1 \quad 164-1 \quad 166-1 \quad 160\rangle\end{array}$ & Puliuentada & $\left|\begin{array}{rr|}1 & 6 \\
28 & =-1 \\
1 & 12\end{array}\right|$ & 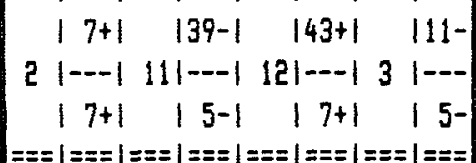 \\
\hline & $==1==$ & $\begin{array}{c}===1===1===1===1===1===1===1=== \\
|1| 1|1| 1|1|\end{array}$ & $\begin{array}{r}=== \pm= \\
\text { TO }\end{array}$ & $\begin{array}{l}===1===1 \\
4851100\end{array}$ & $\mid \begin{array}{l}==|===1===1===|===\mid===1 \\
28|6| 210|43| 186|38|\end{array}$ \\
\hline
\end{tabular}

pétreos de fachadas, principalmente de fábricas, suelen presentar texturas rugosas, y muy escamente las pulimentadas.

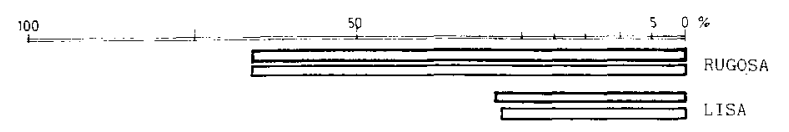

TEXTURA DE LOS MATERIALES (wor tipos)

Е PULIMENTO
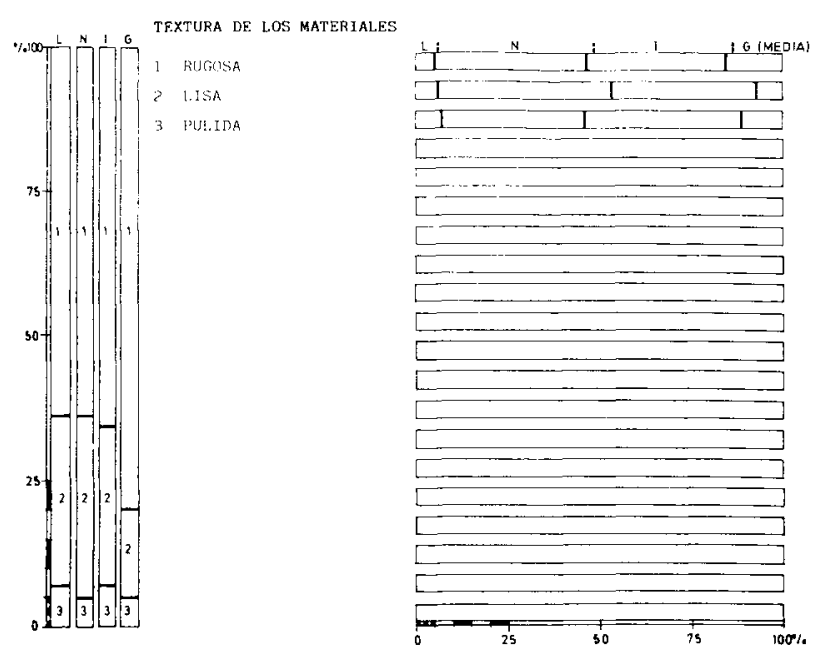

Fig. 14
Las desviaciones con respecto a los valores globales medios no son excesivas, destacando solamente la textura lisa que ofrece un 6 por 100 más de casos leves y normales, lo cual se adapta a los supuestos previos. Sucede lo mismo con la textura rugosa, y aunque la tendencia a incrementarse el valor de $\mathrm{i}+\mathrm{g}$ es baja $(i+g-l-n=2 \%)$, dicha textura acumula el 80 por ciento de todas las lesiones graves.

Para la textura pulimentada, sin grandes desviaciones, se observa contra lo previsto, un aumento de las lesiones intensas. Esto puede explicarse por dos razones: 1.-Los casos datados son pocos (6 por 100 de observados y 12 por 100 del total de fachadas). 2.-En buena parte su elección es debida a que sobre los materiales de textura pulida y color claro se desarrollan lesiones muy destacadas por forma y contraste, pese a que la textura en sí es más sensible al lavado y menor al desarrollo de la pátina (Fig. 14).

\section{INDICE DE RIESGO DE LESIONES}

Con el fin de simplificar y clarificar la lectura de los resultados obtenidos en las correspondientes evaluaciones, he introducido un nuevo factor o instrumento 
de cuantificación del riesgo de lesión asociado a la existencia de cada tipo de variable del proceso. Este "indice de riesgo" lo he obtenido mediante un proceso de aproximación o de tanteo, buscando una manera de relacionar objetivamente cada tipo de variable con la existencia de ensuciamientos de mayor o menor importancia.

Se calcula mediante una expresión matemática que tiene en cuenta la influencia de los porcentajes de calificación resultantes de la evaluación biparametral de las variables implicadas, tal como se han recogido en los cuadros como el expuesto en la página precedente:

$\mathrm{I}=2,22 \cdot \mathrm{K} 1 \cdot \mathrm{l} / 100+1,92 \cdot \mathrm{K} 2 \cdot \mathrm{G} / 100-0,82 \cdot \mathrm{K} 3 \cdot$ $\mathrm{N} / 100-0,36 \cdot \mathrm{K} 4 \cdot \mathrm{L} / 100$

en la que los coeficientes numéricos son valores ponderados de los porcentajes medios de los cuatro tipos de calificaciones. $Y$ las demás variables equivalen a:

$$
\begin{aligned}
& -K_{1}=\left[(\log F I)^{2} \cdot \log I\right] /(\log I 0 \cdot \log F 0) \\
& -K_{2}=\left[(\log F G)^{2} \cdot \log G\right] /(\log G 0 \cdot \log F 0) \\
& -K_{3}=\left[(\log F N)^{2} \cdot \log N\right] /(\log N O \cdot \log F O) \\
& -K_{4}=\left[(\log F L)^{2}-\log L\right] /(\log L O \cdot \log F O)
\end{aligned}
$$

I, G, L y $\mathrm{N}$ son las frecuencias de cada uno de los tipos de calificación para la incidencia de cada uno de los tipos de la variable.

I0, GO, LO y NO son las frecuencias medias para el total de la variable.

$\mathrm{Fl}, \mathrm{FG}, \mathrm{FL}$ y $\mathrm{FN}$ son las frecuencias de cada tipo de variable para el total de la calificación.

F0 es la frecuencia total de aparición de cada tipo de variable.

Asi pues, este indice tiene en cuenta de manera ponderada la aportación de las frecuencias de calificación a cada tipo de variable, utilizando unos coeficientes que penalizan las lesiones según su intensidad, pero también según la distribución de sus frecuencias para el total de la muestra. Además, los tipos de frecuencia se han relacionado con las medidas para incluir el factor acumulativo.

Resumiendo, el índice pone de manifiesto, mediante un número en torno a la unidad, el riesgo que supone la existencia de un determinado factor o caracteristica de una fachada, para que la lesión producida tenga una cierta gravedad y aparezca con una cierta probabilidad. $Y$ caracteriza la importancia del ensuciamiento ponderado con la frecuencia dentro de una muestra específica de casos.

\section{INDICE DE RIESGO GLOBAL O INFLUENCIA DE LA VARIABLE}

Es el parámetro que define no ya el riesgo de los dis. tintos tipos en que se subdivide cada variable del proceso, sino el correspondiente a cada variable conside. rada globalmente $y$, por tanto, como conjunto ponderado de los indices siguientes:

C: $\%$ de referencia igual a $i+g-1-n$ de cada variable.

li: índice de riesgo de cada tipo de las variables.

Fi: frecuencia de cada tipo de las variables.

$K($ indice de influencia $)=(1+C / 100) \cdot \sum_{n}^{i=1}([i \cdot F i)$

Por tanto, se trata de un valor que caracteriza cada factor influyente en el fenómeno de generación de suciedades, así como a la sintomatología y causas del proceso, y que tiene en cuenta los índices de riesgo ponderados con sus frecuencias correspondientes y la incidencia absoluta de las lesiones más importantes.

Con los índices de riesgo y de influencia se confeccionaron diagramas de barras que proporcionan una caracterización visual de los resultados por grupos afines de variables o por la magnitud de riesgo de las mismas.

También se extractaron unas conclusiones referentes a la distribución de dichos índices, de los que, junto a los diagramas antedichos, se incluye una muestra en las páginas siguientes. 
FACTOR DE RIESGO DE CADA VARIABLE (K)

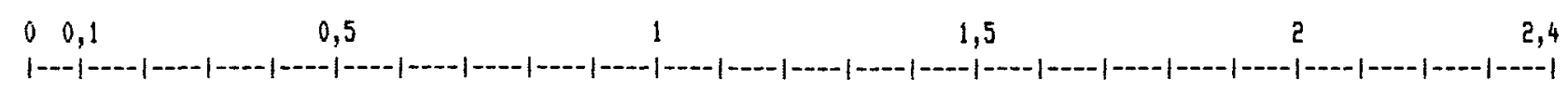

CONDICIONES AHBIENIALES Y GENERALES

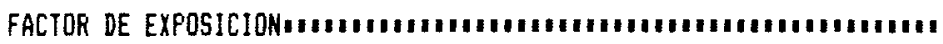

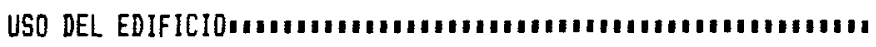

GRADO DE CONTAMINACIONumumumumumumamumamu

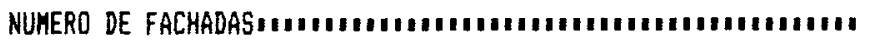

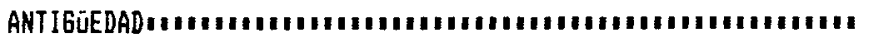

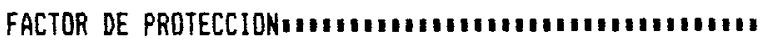

CARACIERISIICAS DE LDS MATERIALES

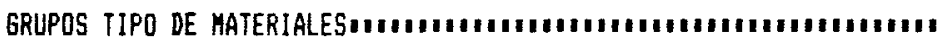

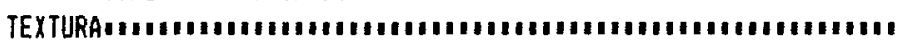

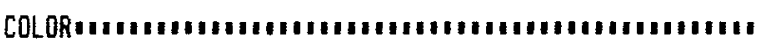

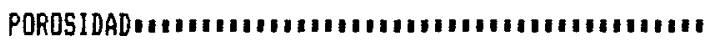

ASOCIACION DE MATERIALESmammanumarmar

TIPOS DE MATERIALESแumumumumamumur

CARACIERISIICAS DE LA FACHADA

CURVATURAn+1,1, RELIEVES DECORATIVOS1,1, INCLINACIONAm, CONJUNTO DE RELIEVESa,1,

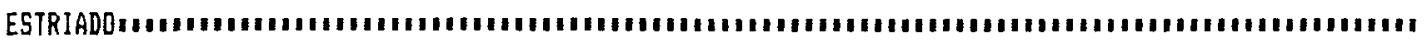

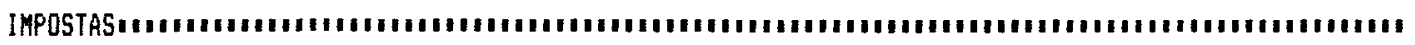

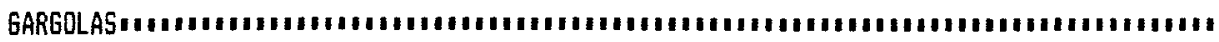

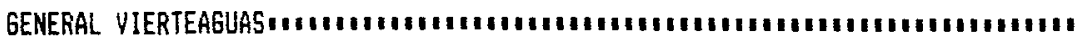

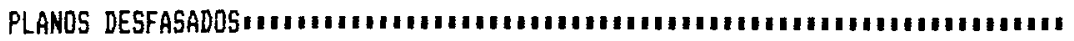

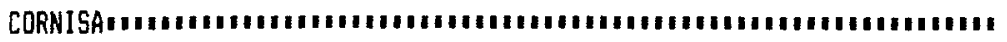

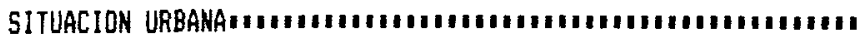

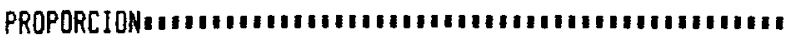

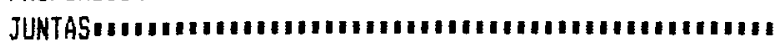

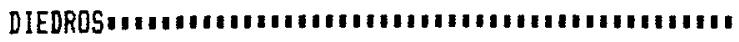

HUECOS DE VENTANAmamanumamamarmama

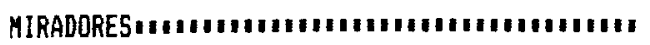

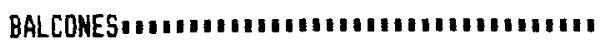

\section{SINTOHAIDLOEIA Y CAUSAS DE LAS SUCLIEDADESS}

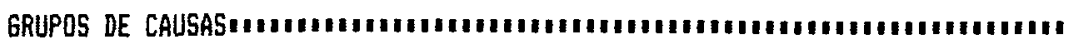

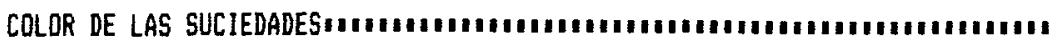

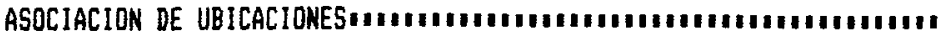

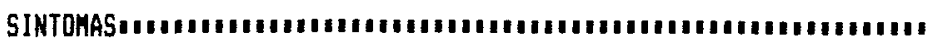

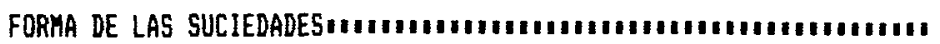

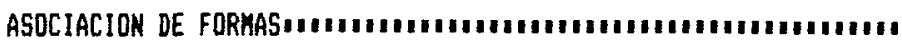

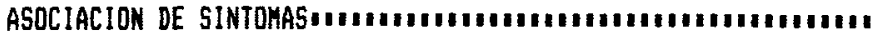
UBICACION DE LAS SUCIEDADESmmammanmmanmmuma! EXTENSION DE LOS SINTOHAS ASOCIACION DE EXTENSIONESmumumumamumumumur ASOCIACIDN DE GRUPOS DE CAUSA5mmammmammammum

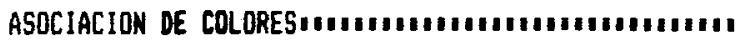
CAUSAS DE LAS SUCIEDADESmmammammanmma 


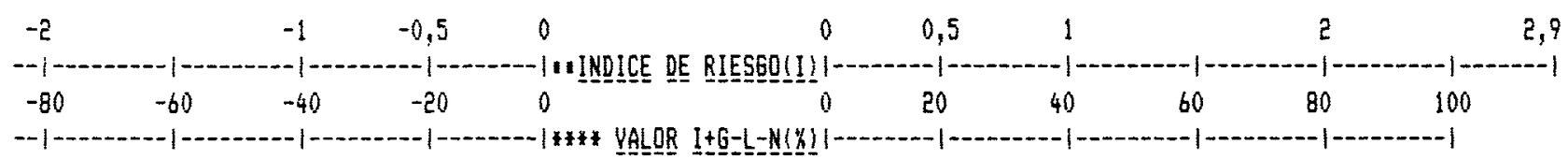

CONDICIONES AHBIENTALES

Factetor de exposicición

NIVEL D

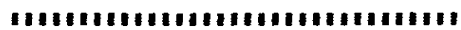

NIVEL 8

\#\#\#*

NIVEL C

munumum

\#*

\#**

mannan

Uso del edificic

RELI61050

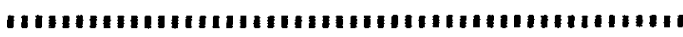

MONUMENTAL

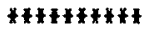

MONURENAL

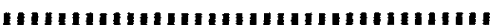

DOCENTE

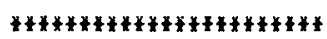

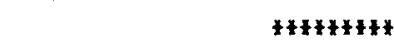

RESIDENCIAL COLECT, manmmmmmmanmm,mm

\$\$廿\$\$\$\$\$\$\$\$\$

COMERCIAL

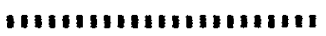

VIVIENDAS

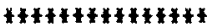

\#\#\#+\$*

OFICINAS

Minumin

\$\#*

Grado de contaginación

\begin{tabular}{|c|c|}
\hline \multirow[t]{2}{*}{ MEDIO } & 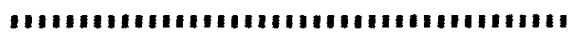 \\
\hline & $* * * * * * * * * * * * * *$ \\
\hline \multirow[t]{2}{*}{ ALTO } & 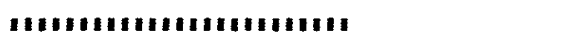 \\
\hline & * \\
\hline KODERADO/BAJO & manimentin \\
\hline
\end{tabular}

Mmommman NULO

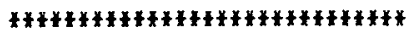

Núnero de fachadas

\begin{tabular}{|c|c|}
\hline \multirow[t]{2}{*}{ TRES } & 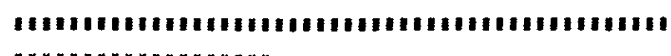 \\
\hline & 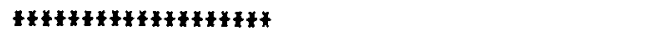 \\
\hline CUATRO & mommontmomoms \\
\hline DOS & $\begin{array}{l}\text { *\#\#* } \\
\text { mumbummum }\end{array}$ \\
\hline * & \\
\hline UNA & mis \\
\hline
\end{tabular}




\section{3. ${ }^{\mathrm{a}}$ PARTE: CONCLUSIONES Y PROPUESTAS}

La elaboración de resultados y su comparación con las hipótesis de partida, han sido bastante reveladores, según mi entender, aunque sin pretender ser exhaustivas. Pero han permitido alcanzar algunas conclusiones generales:

- La comparación de los resultados obtenidos, tras el análisis de las fachadas de Valladolid, con los fundamentos establecidos en la primera parte del estudio permite afirmar que, en su mayor parte, dichas hipótesis son válidas. Algunas desviaciones habidas, especialmente las referentes a cuestiones básicas, deben investigarse con mayor detenimiento, considerando lo arriesgado de justificaciones simplistas, a tenor de las tres razones repetidamente apuntadas: naturaleza de la selección de la muestra, escasa incidencia eventual de ciertas variables en cuestión y la sencillez de un análisis que tiene en cuenta dos variables, cuando muchas más suelen hallarse im. plicadas.

- El tipo de contaminante principal causante de la formación de depósitos de suciedad es el humo procedente de la combustión de los motores de vehículos automóviles, especialmente los denominados "Diesel", en estrecha correlación con las circunstancias derivadas de la aglomeración del tráfico y de las características urbanas por donde discurre. Otros contaminantes clásicos, como los humos de calefacciones y el polvo atmosférico inciden más arbitrariamente según ciclos temporales y caracteres climáticos.

- El grado de contaminación, con ser el elemento desencadenante y causante inmediato del fenómeno, resulta, a la postre, mediatizado por otros dos: las características que definen el ambiente del edificio (clima, trama urbana, etc.) y por los caracteres materiales y compositivos de las fachadas.

- Sobre los materiales pétreos de revestimiento elegidos para el estudio, dos se hallan fundamentalmente asociados, en Valladolid, con los deterioros más evidentes: piedra caliza de la región y elementos de hormigón premoldeados, muy dispares en cuanto a su naturaleza y a las consecuencias del ensuciamiento, lo cual indica que un buen número de motivos han coadyuvado a este resultado. Los otros dos tipos de materiales, cerámica y morteros, transmiten una sensación de hallarse menos afectadas por las alteraciones en cuestión.

- La influencia del microclima general de Valladolid sobre la formación de suciedades no resulta fácil de precisar sin poseer datos análogos de otras ciuda. des. Aun cuando ciertos meteoros componentes de dicho clima afectan inmediatamente al proceso a través del factor de exposición, éste se halla también mediatizado por la organización de la ciudad, con el resultado de situaciones bien dispares si se trata de edificios suburbanos, menos afectados que aquellos que radican en el seno de la parte más tortuosa del casco antiguo.

- Una conclusión recurrente de todo el estudio, tal co. mo se sugiere en el punto anterior, es la interrelación de influencia entre las variables consideradas, aunque más concretamente de los conjuntos afines de variables, esto es, la existente entre el grado de contaminación, los factores climáticos y ambientales, las características compositivas de la fachada y las de los materiales que las revisten.

- Como corolario de lo anterior, y en aras de una simplificación del estudio y mayor facilidad para la adop. ción de un conjunto coherente de medidas preventivas o correctoras, apunto la racionalidad e interés práctico de abordar el problema del ensuciamiento a partir de la fijación de unos modelos de sujetos que abarcasen determinados tipos de grupos de variables, principalmente aquellos cuya mayor incidencia ha quedado demostrada a lo largo del presente estudio.

- Sin detrimento de la conclusión precedente, cabe afirmar que los parámetros con influencia fundamental en el proceso, por hallarse frecuentemente relacionados con los tipos de suciedades menos aceptables, son los directamente relacionados con la macrotextura y morfologia de las fachadas (especial. mente la disposición de los planos y ciertos tipos de relieves), es decir, algunos factores pertenecientes al campo específico del diseño.

Con todos estos antecedentes cabe proponer una última y decisiva conclusión que viene a constituir la verificación de la hipótesis general de partida.

- La solución compositiva y constructiva de las fachadas es el elemento clave interviniente en el proceso de ensuciamiento y en el modo en que evoluciona su aspecto con el transcurso del tiempo. Por consiguiente, en tanto en cuanto dicha solución forma par. te del proyecto global del edificio, se concluye que los arquitectos tienen en su mano la posibilidad de actuar en esa dirección para evitar aquellos errores de bulto que pueden conllevar una maduración de. sastrosa de la imagen de sus edificios y, eventualmente, un deterioro prematuro de los materiales de revestimiento. Esto incluso asumiendo la cuota de incertidumbre del fenómeno y el variable grado de libertad de las decisiones de los arquitectos en un contexto social general de indiferencia ante problemas de semejante indole. 


\section{SUGERENCIAS PARA EL PROYECTO}

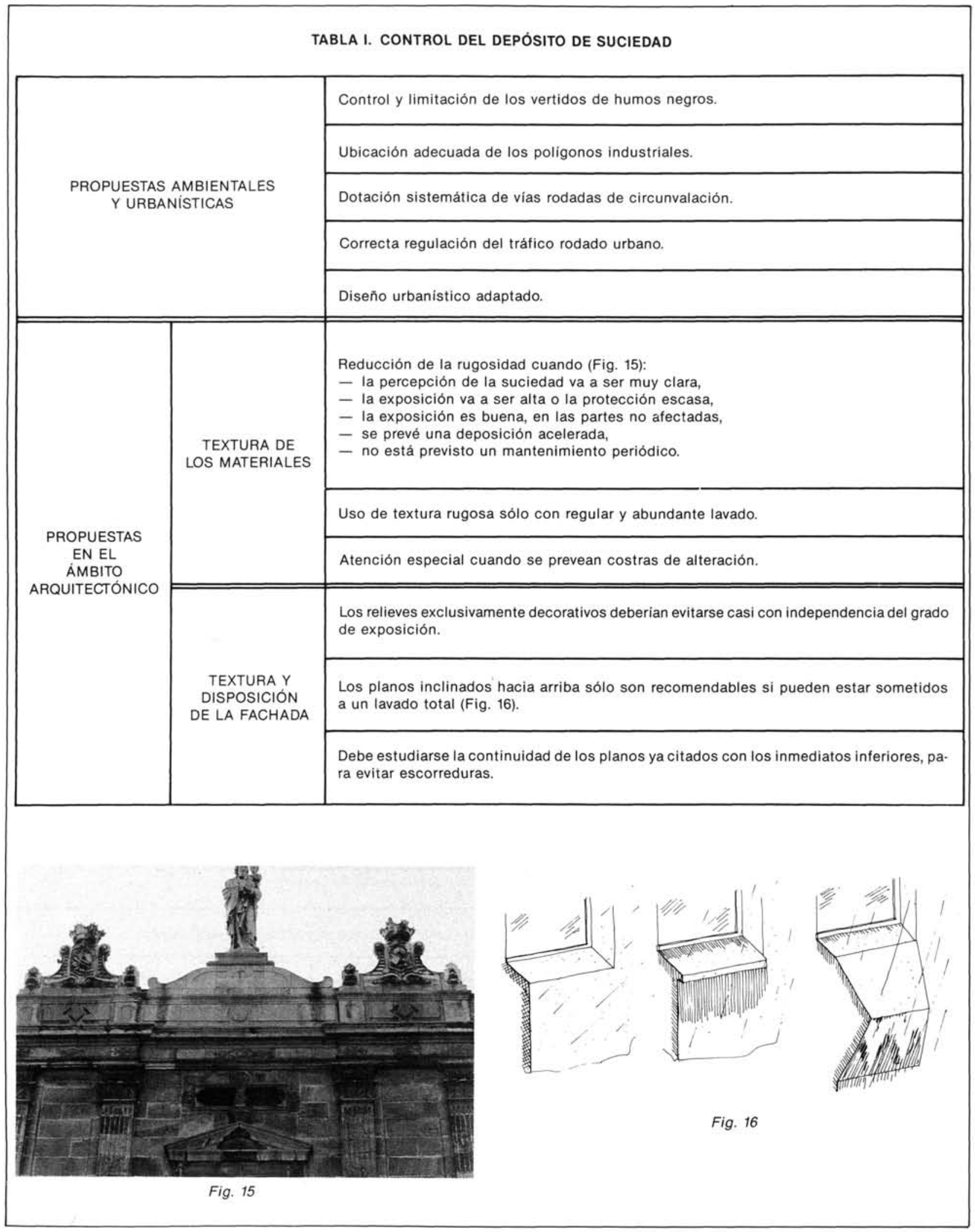


TABLA II. CONTROL DE LA ELIMINACIÓN Y REDISTRIBUCIÓN DE LA SUCIEDAD

\begin{tabular}{|c|c|c|c|}
\hline \multicolumn{2}{|c|}{ II.a FACHADAS NO LAVADAS } & $\begin{array}{l}\text { Aceptables } \\
\text { salvo: }\end{array}$ & $\begin{array}{l}\text { - con revestimientos calcáreos en ambientes sulfurosos. } \\
\text { - con texturaciones muy fuertes de los materiales o la fachada. } \\
\text { - si presentan componentes saledizos sensibles al lavado diferencial (Fig. 17). }\end{array}$ \\
\hline \multicolumn{4}{|c|}{ II.b FACHADAS SOMETIDAS A LA ACCIÓN DEL VIENTO/LLUVIA } \\
\hline \multirow{20}{*}{$\begin{array}{l}\text { CONTROL } \\
\text { DEL AGUA } \\
\text { DE LLUVIA } \\
\text { DIRECTA }\end{array}$} & \multirow{3}{*}{\multicolumn{2}{|c|}{ FACTOR DE EXPOSICIÓN }} & Siempre es preferible una exposición elevada. \\
\hline & & & El grado de exposición puede ser indiferente si la protección es elevada. \\
\hline & & & En edificios exentos la exposición puede ser muy variable según fachadas. \\
\hline & \multirow{3}{*}{\multicolumn{2}{|c|}{ FACTOR DE PROTECCIÓN }} & Es aconsejable el menor factor de protección posible. \\
\hline & & & Distintos niveles de protección en una misma fachada son peligrosos. \\
\hline & & & La protección total actúa como una exposición muy baja. \\
\hline & \multirow{14}{*}{$\begin{array}{l}\text { CARACTERES } \\
\text { DE LAS } \\
\text { FACHADAS }\end{array}$} & \multirow{3}{*}{ CORNISAS } & Ligeros vuelos o relieves sólo protegen de la lluvia cuando hay calma. \\
\hline & & & $\begin{array}{l}\text { Interesan vuelos amplios que serán más efectivos cuando (Fig. 18): } \\
\text { - la velocidad del viento es menor, } \\
\text { - la fachada está más abrigada (factores } \vee \text { y } X \text { ), } \\
\text { - la exposición es escasa (factor } D \text { ). }\end{array}$ \\
\hline & & & En la cornisa los planos horizontales o muy inclinados son peor lavados. \\
\hline & & \multirow{2}{*}{ IMPOSTAS } & Similares condiciones que para la cornisa. \\
\hline & & & Son más efectivas cuando se distribuyen varias en la altura de fachada. \\
\hline & & $\begin{array}{l}\text { OTROS } \\
\text { COMPO- } \\
\text { NENTES } \\
\text { VOL. }\end{array}$ & $\begin{array}{l}\text { Desfases, balcones y miradores: más eficaces si son corridos, saledizos y dispuestos } \\
\text { uniformemente en la fachada. }\end{array}$ \\
\hline & & \multirow{6}{*}{$\begin{array}{l}\text { INCLINA- } \\
\text { CIÓN } \\
\text { VERTICAL } \\
\text { DE LOS } \\
\text { PLANOS }\end{array}$} & $\begin{array}{l}\text { Hacia arriba: facilita el lavado en las plantas inferiores. En las altas no es necesario. De- } \\
\text { be asegurarse el lavado total de los planos afectados. }\end{array}$ \\
\hline & & & $\begin{array}{l}\text { Los planos aislados requieren lavado completo o mantenimiento periódico. } \\
\text { Deben estar provistos de interruptores de escorrentía. }\end{array}$ \\
\hline & & & Son interesantes cuanto más rugoso sea el material de revestimiento. \\
\hline & & & Hacia abajo: para lograr pátina uniforme si se evitan escorreduras (Fig. 19). \\
\hline & & & Son preferibles con texturas lisas. \\
\hline & & & Los planos curvos son desaconsejables (Fig. 20). \\
\hline & & \multirow[b]{2}{*}{$\begin{array}{l}\text { DIEDROS } \\
\text { VERTICALES }\end{array}$} & El control del ángulo diedro permite regular el nivel de exposición. \\
\hline & & & $\begin{array}{l}\text { En superficies curvas: recomendable el control del radio de curvatura y la utilización de } \\
\text { combinaciones de planos cóncavos y convexos. }\end{array}$ \\
\hline
\end{tabular}




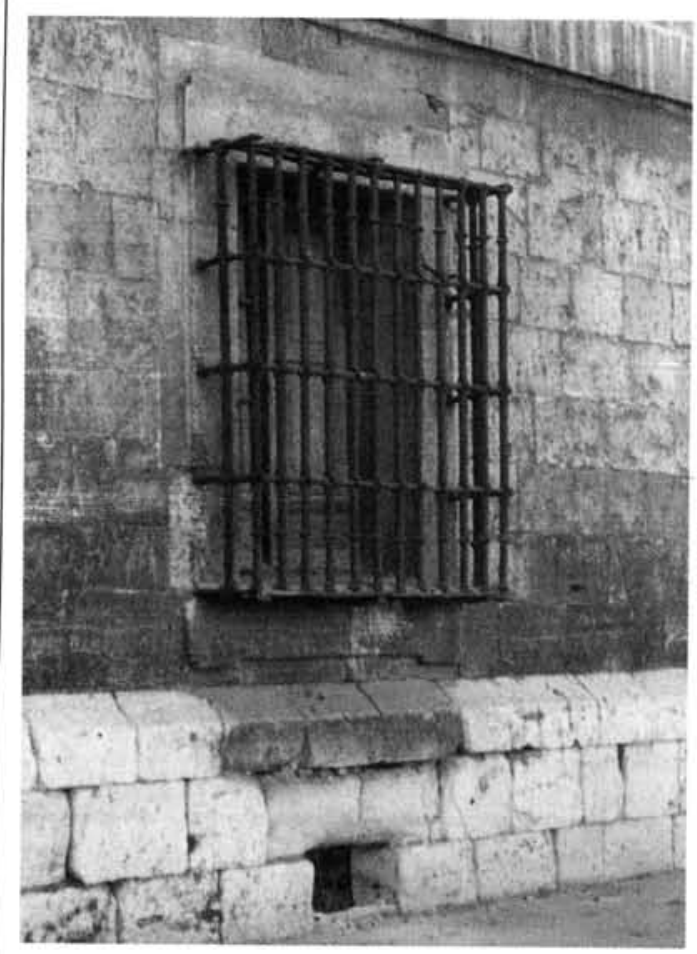

Fig. 17
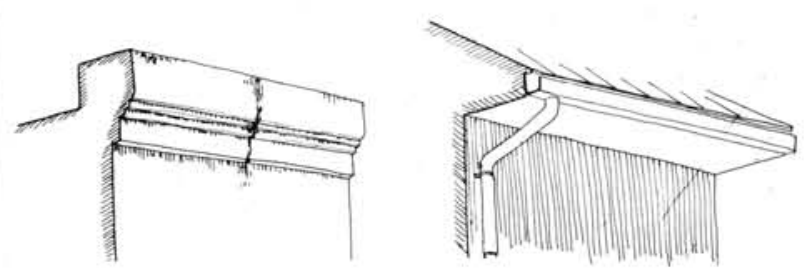

Fig. 18

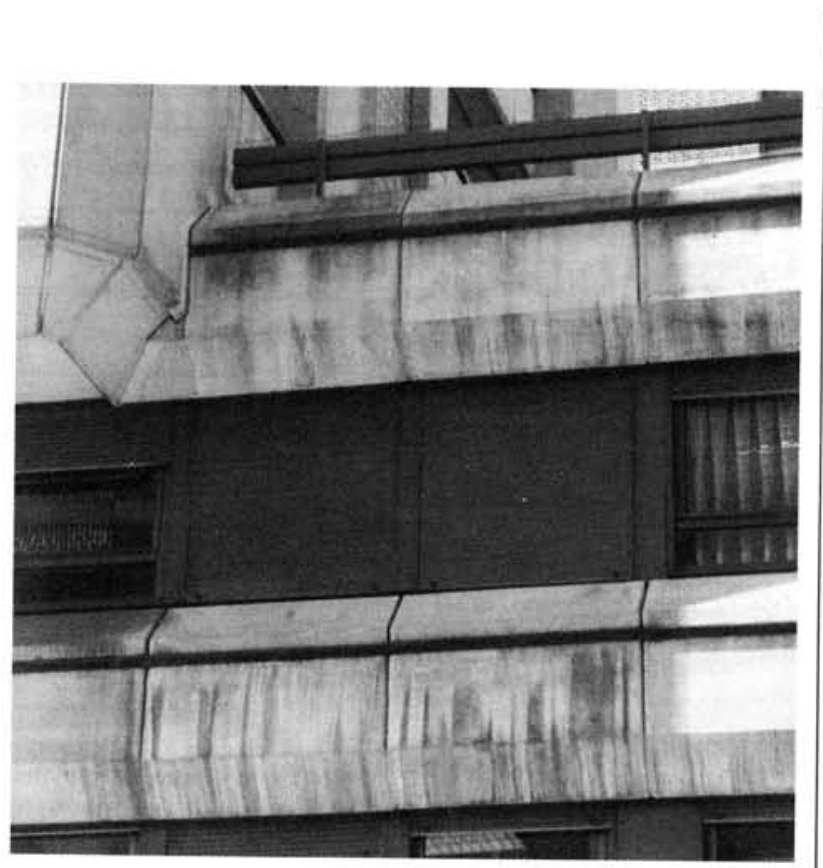

Fig. 19

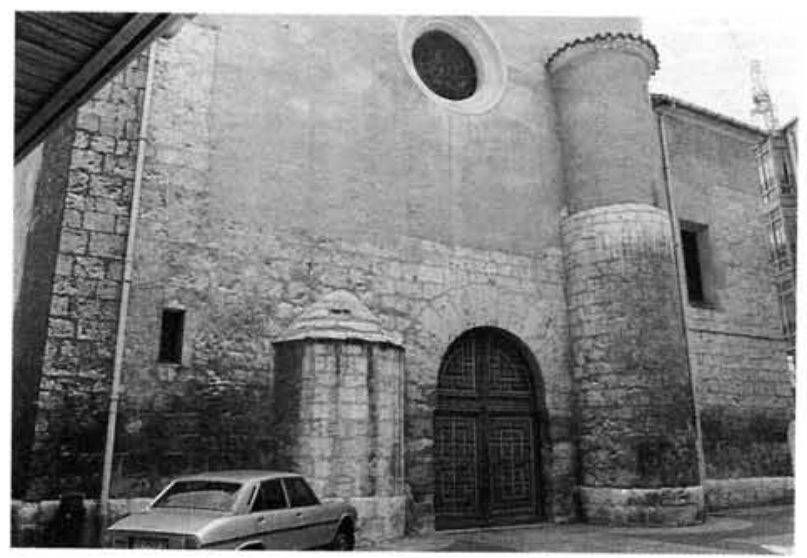

Fig. 20

\begin{tabular}{|c|c|c|c|}
\hline \multirow{3}{*}{$\begin{array}{c}\text { CONTROL } \\
\text { DEL AGUA } \\
\text { DE LLUVIA } \\
\text { DIRECTA }\end{array}$} & \multirow{3}{*}{$\begin{array}{l}\text { CARACTERES } \\
\text { DE LAS } \\
\text { FACHADAS }\end{array}$} & \multirow{3}{*}{$\begin{array}{l}\text { SITUACION Y } \\
\text { PROPORCION }\end{array}$} & Si son fachadas entre medianerias, las mismas consideraciones anteriores. \\
\hline & & & $\begin{array}{l}\text { Fachadas exentas: recomendable la máxima esbeltez cuanto mayor sea la desprotec- } \\
\text { ción; y minima cuando la edificación deba ser en horizontal. }\end{array}$ \\
\hline & & & $\begin{array}{l}\text { Edificios en esquina: } \\
\text { - Preferible la máxima esbeltez; si no, medios para equilibrar el lavado. } \\
\text { - En edificios en trama cerrada con una fachada protegida, hay que actuar sobre la } \\
\text { afectada, igual que en el caso precedente. } \\
\text { - En fachadas con distintas proporciones, conocido el comportamiento, convienen las } \\
\text { medidas anteriores o bien otras para el enmascaramiento. }\end{array}$ \\
\hline
\end{tabular}


II.b FACHADAS SOMETIDAS A LA ACCION DEL VIENTO/LLUVIA (continuación)

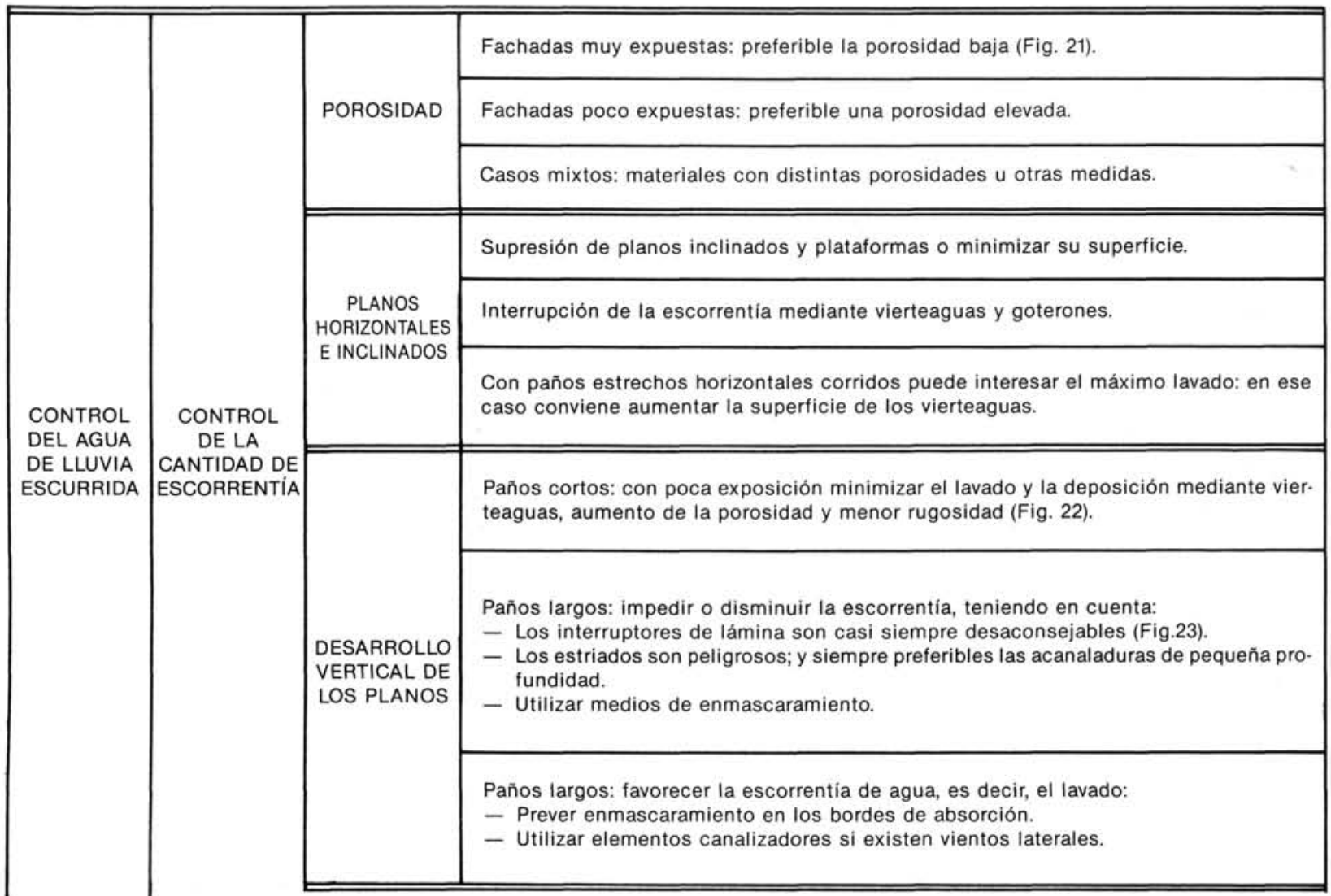
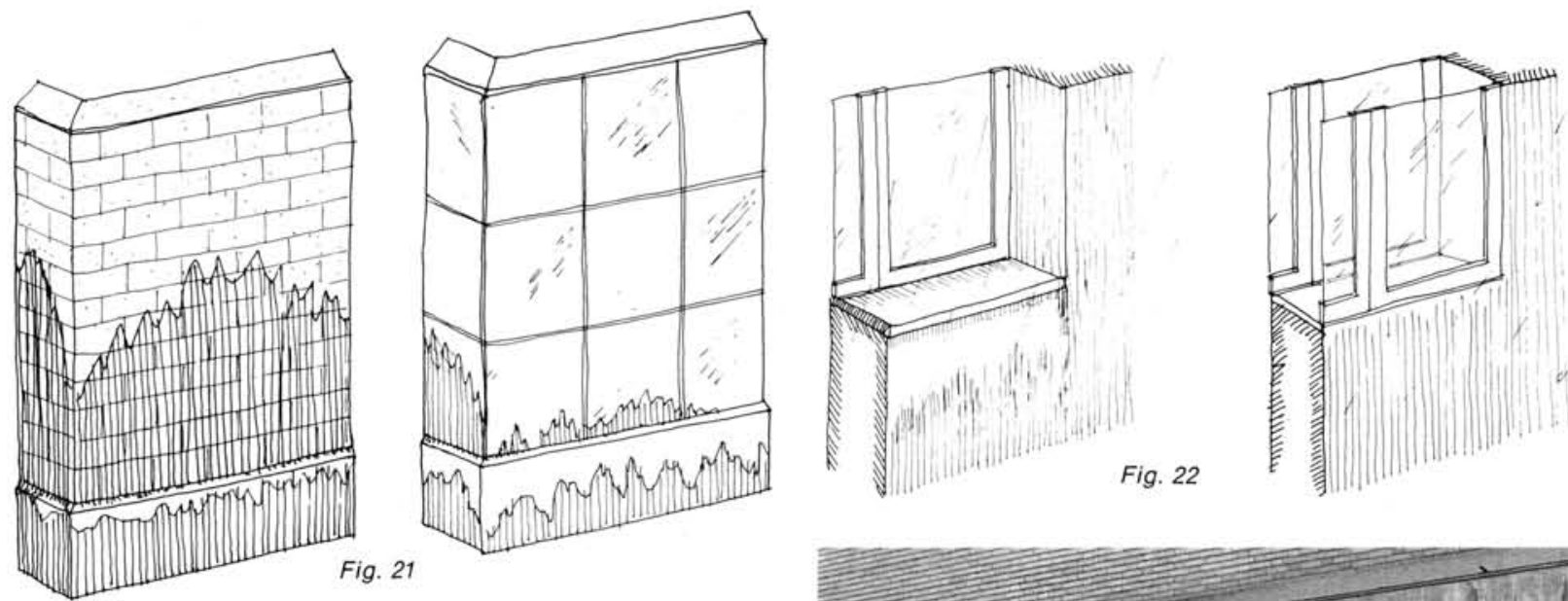

Fig. 21
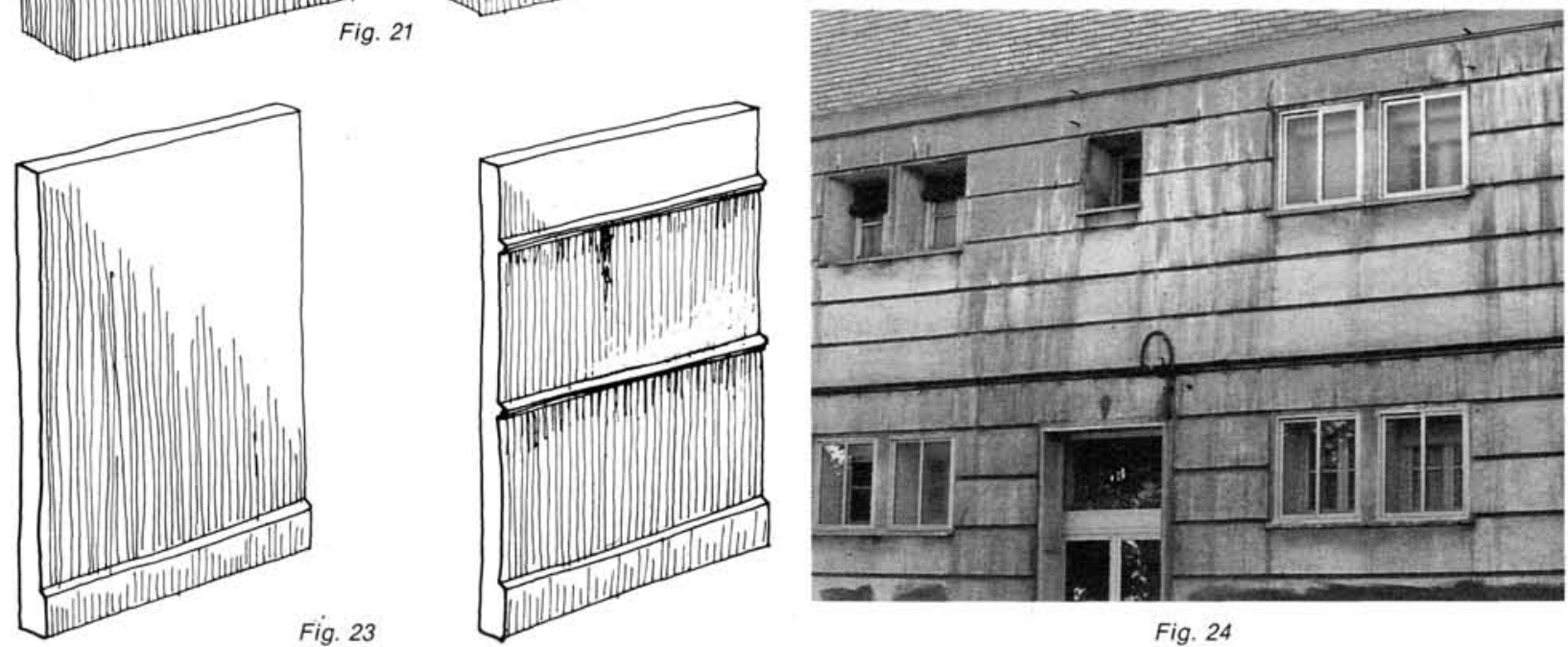

Fig. 23

Fig. 24

(c) Consejo Superior de Investigaciones Científicas Licencia Creative Commons 3.0 España (by-nc) 
II.b FACHADAS SOMETIDAS A LA ACCION DEL VIENTO/LLUVIA (continuación)

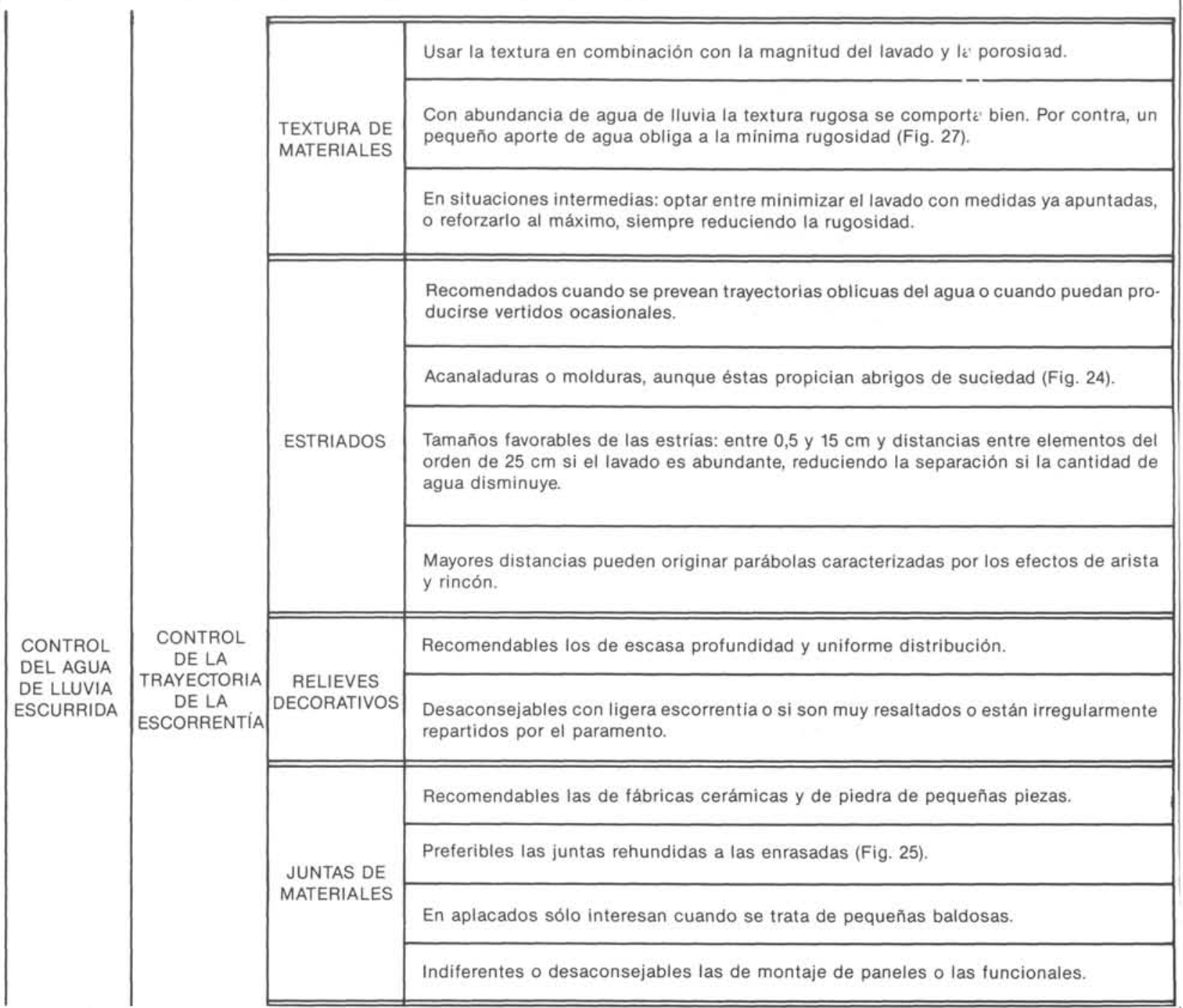
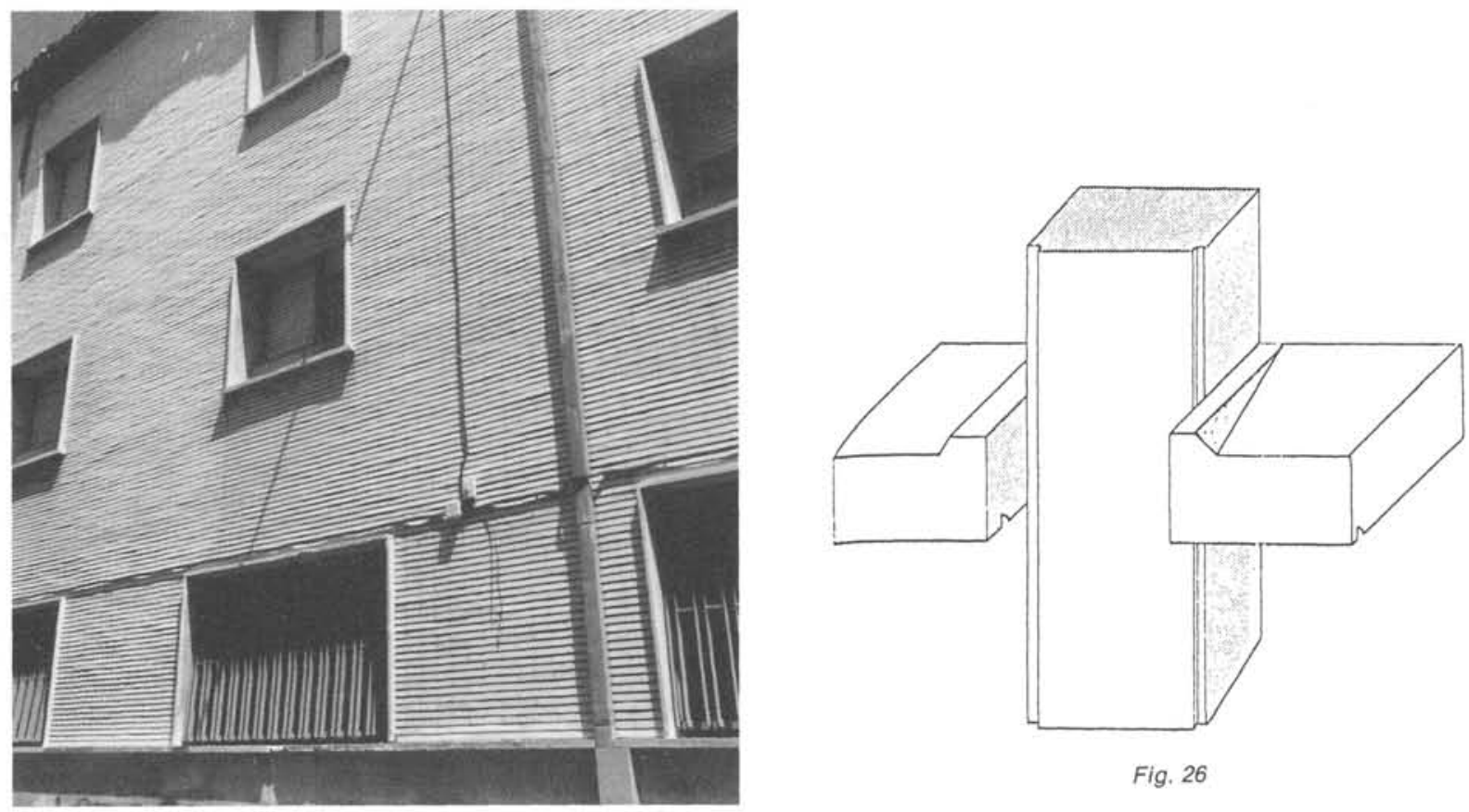

Fig. 26

Fig. 25

(c) Consejo Superior de Investigaciones Científicas Licencia Creative Commons 3.0 España (by-nc) 


\begin{tabular}{|c|c|c|c|}
\hline \multirow{9}{*}{$\begin{array}{l}\text { CONTROL } \\
\text { DEL AGUA } \\
\text { DE LLUVIA } \\
\text { ESCURRIDA }\end{array}$} & \multirow{2}{*}{$\begin{array}{c}\text { CONTROL } \\
\text { DE LA } \\
\text { TRAYECTORIA } \\
\text { DE LA } \\
\text { ESCORRENTIA }\end{array}$} & \multirow[b]{2}{*}{ ENCUENTROS } & $\begin{array}{l}\text { Todo encuentro de componentes importantes de fachada, sobresalientes o rehundidos, } \\
\text { comporta un peligro para la imprevisible o compleja respuesta ante el ensuciamiento } \\
\text { y los vertidos de agua. }\end{array}$ \\
\hline & & & $\begin{array}{l}\text { Como reglas básicas pueden apuntarse las siguientes: } \\
\text { - Prever, por sisterna, vierteaguas y goterones según el aporte de agua. } \\
\text { - Transformar aristas vivas y rincones en diedros en chaflán o biselados para evitar } \\
\text { concentraciones o parábolas acusadas de suciedad (Fig. 26, pág. anterior). } \\
\text { - Utilizar otras medidas de enmascaramiento, como textura, relieves, color, etc., si las } \\
\text { anteriores no son posibles. }\end{array}$ \\
\hline & \multirow{7}{*}{$\begin{array}{l}\text { CONTROL } \\
\text { DE LA } \\
\text { REDISTRIBUCION } \\
\text { DE SUCIEDAD }\end{array}$} & \multicolumn{2}{|c|}{$\begin{array}{l}\text { La mayoria de los redepósitos ocurren en la mitad inferior del edificio si el aporte de agua es abundan- } \\
\text { te. Si es escaso y la porosidad alta, pueden aparecer en coronación. }\end{array}$} \\
\hline & & \multicolumn{2}{|c|}{$\begin{array}{l}\text { Si la escorrentia es importante basta con favorecer el deslizamiento y autolavado por textura y porosi- } \\
\text { dad, intentando disimular los bordes de absorción de la lámina. }\end{array}$} \\
\hline & & \multicolumn{2}{|c|}{$\begin{array}{l}\text { Con pequeño volumen de agua escurrida puede interesar el aumento de la porosidad del material (si } \\
\text { no va a afectar sensiblemente a la durabilidad) o utilizar medidas para ocultar las bandas de reacumula- } \\
\text { ción de suciedad. }\end{array}$} \\
\hline & & \multicolumn{2}{|c|}{ Evitar plataformas inaccesibles y disponer drenajes. } \\
\hline & & \multicolumn{2}{|c|}{ Diseño y ejecución correctos de los elementos de vierteaguas. } \\
\hline & & \multicolumn{2}{|c|}{$\begin{array}{l}\text { Evitar los aditamentos o elementos extraños a la fachada (cableados, letreros, etc.), que ocasionan ine- } \\
\text { vitables depósitos de particulas y escorreduras. }\end{array}$} \\
\hline & & \multicolumn{2}{|c|}{ Emplear procedimientos complementarios de enmascaramiento. } \\
\hline
\end{tabular}

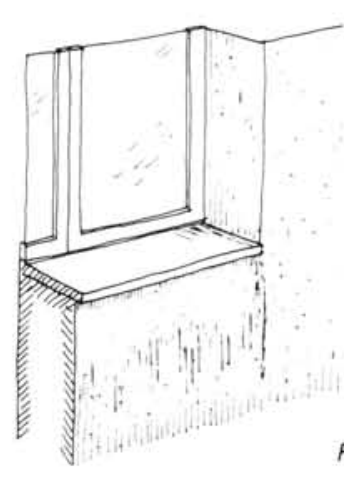

Fig. 27
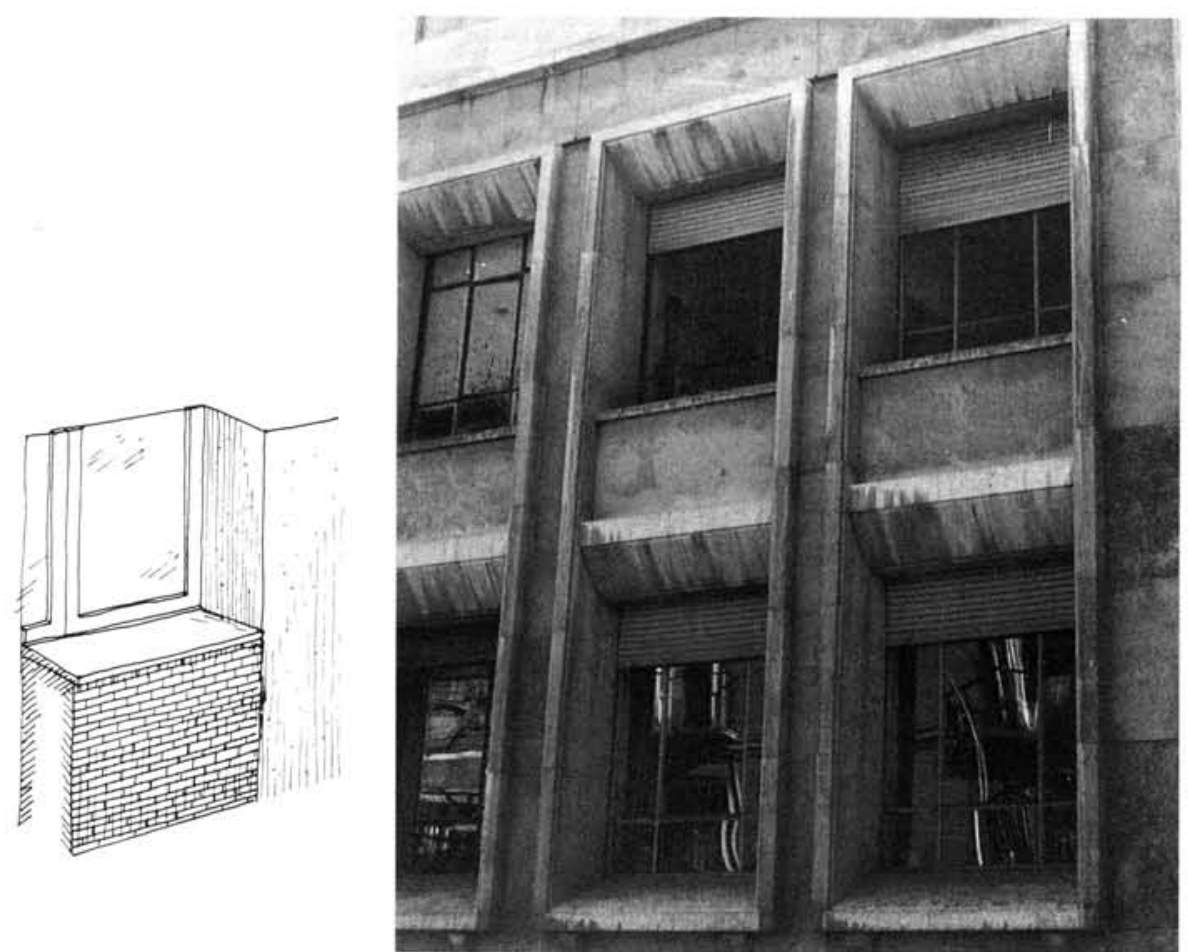

Fig. 28 
TABLA III. CONTROL DEL GRADO DE MANIFESTACIÓN/PERCEPCIÓN DE LA SUCIEDAD

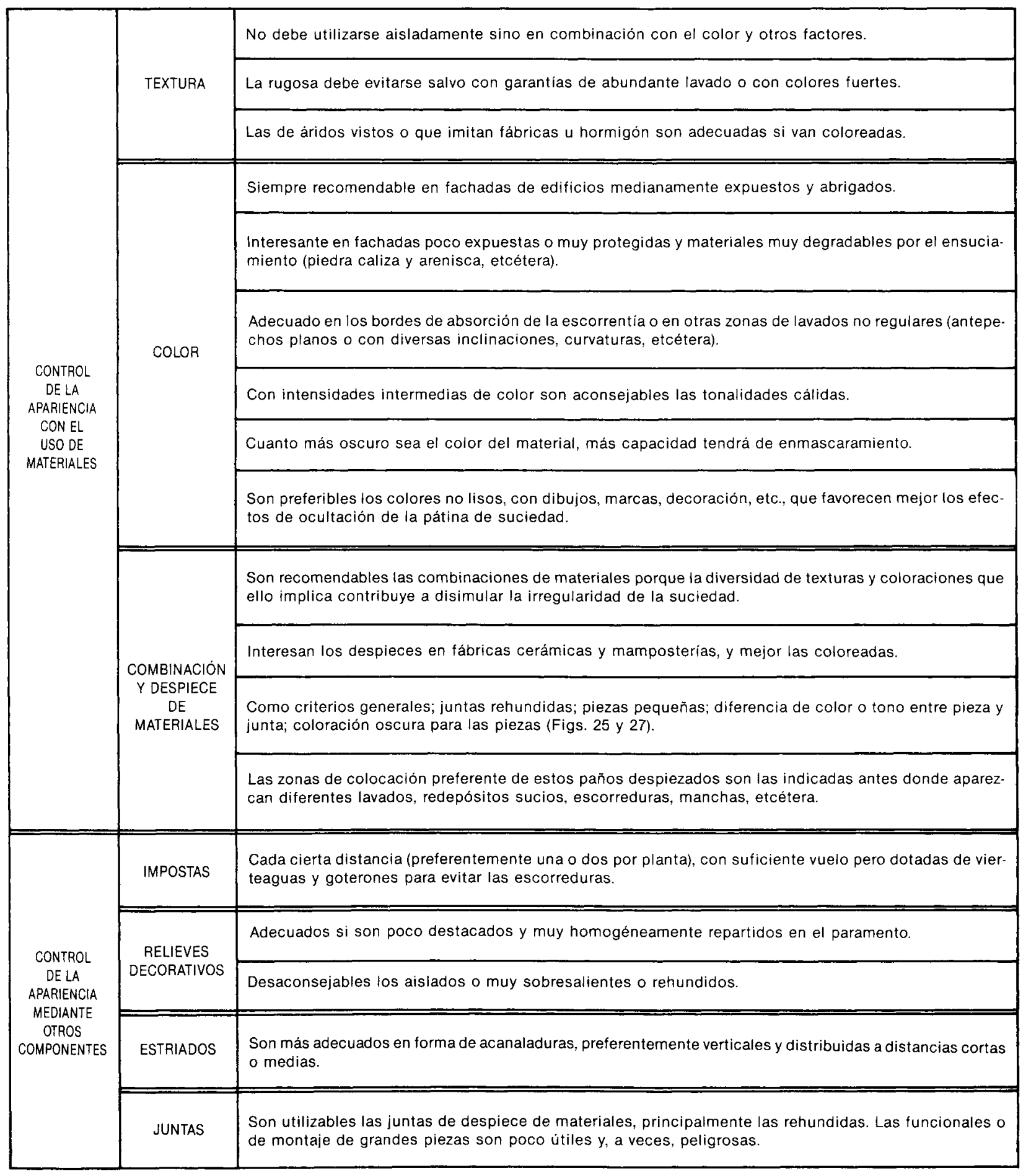




\section{REFERENCIAS BIBLIOGRAFICAS}

1. SALISSURES DE FAÇADES. C. Carrié/D. Morel. Eyrolles (París, 1975).

2. STONE DECAY AND CONSERVATION. Amoroso/Fassina. Elsevier (Amsterdam, 1983).

3. WEATHERING ON EXTERNAL WALLS OF CONCRETE. O. Beijer. CBI report n. ${ }^{\circ} 11$ (1980).

4. PATOLOGIA DE FACHADAS: SUCIEDADES. J. Monjo Carrió. Apuntes Cátedra Construcción IV ETSAV (1981).

5. SURVEY OF 62-SCF COMMITEE. E. M. Theissing. CIBRILEM (1984).

6. DISEÑO DE FACHADAS DE HORMIGÓN ARQUITECTÓNICO. Avellaneda/Cuchi/Zamora. Los autores/ESCOFET (1980).

7. WIND-DRIVEN RAIN AND BUILDINGS. Robinson/Baker. Technical Paper n. ${ }^{\circ}$ 11. DBR NRCC. Ottawa, 1975.
8. CONCRETE WALLS AND WEATHERING. O. Beiger. Swedish Cement and Concrete Research Institute (1977).

9. PATOLOGÍA DE FACHADAS. Departamento de Construcciones Arquitectónicas, E.T.S.A. Valladolid. Universidad de Valladolid/Caja Ahorros de Salamanca, 1987.

10. TEST ON LIMESTONE WEATHERING. E. Orcsik/M. Zador. International Symposium. Deterioration and Protection of Stone Monuments. UNESCO-RILEM. Paris (1978).

11. SOILING AND CLEANING OF BUILDING FAÇADES. Reporte of 62-SCF Committe. CIB-RILEM (1988).

12. LA LIMPIEZA DE LAS PIEDRAS DE CONSTRUCCIÓN. Francisco Ortega Andrade. Revista $Q$ del C. S. Colegios de Arquitectos (dic. 83).

13. INFLUENCE DES NUISANCES URBAINES SUR LA DE. GRADATION DES INMEUBLES ANCIENS. Faugere/Duffau/ Salineres/Dufur. VI Congrès Mondial pour la Qualité de l'air. París, 83.

\title{
publicación del ICCET/CSIC
}

\author{
ALOJAMIENTO Y TECNOLOGÍA: \\ ¿INDUSTRIALIZACIÓN ABIERTA? \\ Julián Salas Serrano
}

La experiencia nacional en construcción industrializada en la última década, aunque no abundante. puede resultar paralizante. Como reacción, este trabajo trata de elaborar y ordenar la información que pegado al terreno, se ha acumulado durante los sesenta.

Auscultando tendencias avanzadas en otros paises y apoyándose en nuestra realidad cotidiana, el autor de este trabajo apuesta por la industrialización, presintiendo un futuro con pocos puntos en común con lo que en general, hasta bien reciente, se ha conocido como construcción industrializada.

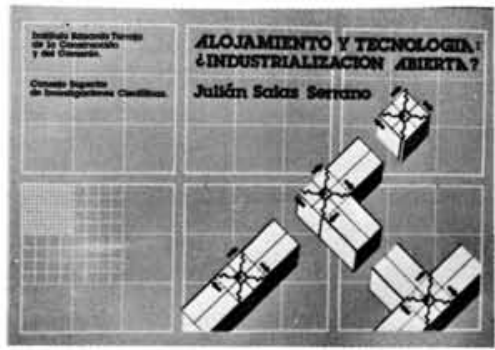

Se abre el trabajo con un prólogo del Profesor Ciribini en el cual, con rigor conceptual y desde su rica experiencia, analiza algunos de los conceptos más polémicos del fenómeno de industrialización del sector construcción. El autor recopila un conjunto de aportaciones de maestros de la arquitectura al lento proceso de evolución tecnológica y conceptual, continuando con un intento de respuesta realista a la interrogante que flota en el sector nacional: ¿réquiem por la industrialización?

Se dedican otros capítulos a revisar lo realizado y a encarar el futuro inmediato: el concepto de componente, su repercusión económica, la dificultad del proyecto a base de productos industriales, la nueva vigencia embrionaria de la construcción por medio de catálogos, los conceptos de flexibilidad e intercambiabilidad desde una óptica práctica. Especial atención dedica este trabajo a la exposición de lo que podiamos llamar nuevos derroteros de la coordinación dimensional, aportando una visión actualizada y pragmática de los enfoques más implantados en Europa.

Las siempre problemáticas interrelaciones entre normativa, calidad e industria se detallan de forma documentada y realista. Finaliza el trabajo con unas reflexiones dirigidas al ámbito empresarial y un esbozo de «reglas de juegon que faciliten al subsector la salida del kimpassen actual.

Un volumen encuadernado en rústica, de $24 \times 16,5 \mathrm{~cm}$, compuesto de 160 páginas, con 109 figuras, 19 tablas y 86 referencias bíbliográficas. Madrid, junio, 1981 .

Precios: España 1.200 PTAS. Extranjero 19 \$ USA. 